\title{
Davao Conyo invasion: A morpho-semantic analysis
}

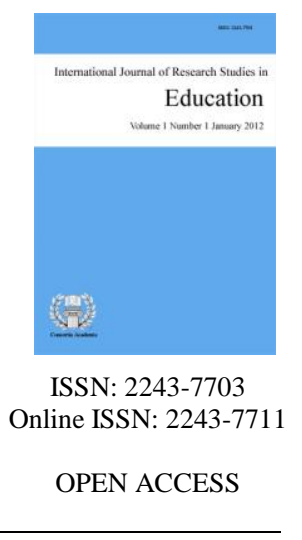

Mojica, Darla Regine Salve

Department of Education, Davao de Oro Division, Philippines (darlaregine.mojica@deped.gov.ph)

De Leon, Maria Guadalupe M.

University of Mindanao, Tagum, Philippines (guadadeleon 810@yahoo.com)

\section{Abstract}

This study aimed to determine which domain in the social support significantly influenced the learning and development of grade six students. The quantitative, non-experimental design utilizing causal effect was used in the study. The respondents were the 179 grade six students from Zone two of New Corella District in the Division of Davao del Norte who were chosen through random sampling. Mean, Pearson-r, and Linear Regression Analysis were the statistical tools used in the study. This study revealed that the social support to grade six students in terms of family, peers and nonrelative adult was very high. Also, student learning and development was very high in terms of physical health and well-being, social connectedness, social and emotional development, school experiences, and use of after school time. The correlation coefficient between variables of this study revealed very high positive significant relationship between social support and student learning and development. Nonrelative adult support revealed as the domain of social support that best predicted the student learning and development of grade six students.

Keywords: teaching English, Davao Conyo language, discourse analysis, morphosemantic analysis, Philippines 


\section{Davao Conyo invasion: A morpho-semantic analysis}

\section{Introduction}

As stated in the Article XIV, Section 6 of the 1987 Philippine Constitution, "Filipino is the national language of the Philippines. As it evolved, it shall be further developed and enriched on the basis of existing Philippine and other languages". The growing Filipinos had accompanied the widespread on borrowing of the lexical from the usage of the English language for the information and communication purposes by having a lesser level from Philippine and foreign languages being used and the "Tagalog-English code switching" which was commonly known as Taglish. Moreover, the Tagalog varieties of Filipino from Metro Manila (FMM) was coming into being. This frequently referred to as FMM, which had finally originated out that the ways were applied to the other portions of the country by means of social media, local movie, and to the educational institutions. Non-Tagalog users of Filipino were used the rules of their respective dialects and this was becoming the case of Filipino speakers who lived in Davao City (Bautista, 2004 as cited by Rubrico, 2014).

Because of the sturdy linguistic influences that had been brought which had resulted from contacting to the different people and various culture, the word or a phrase can be taken on different meanings. Interpretations among a group of individuals based on its original connotation of "a meeting of cultures in the intercultural domain that resulted in irreversible intracultural alterations (Mey, 2007). The situation was usually observed among multilinguals who usually developed functions of linguistic heterogeneity which go beyond the expressive possibilities available in a single code and most cases of their translations or interpretations were signified to its figurative fate (Garvida, 2012).

Similarly, the spreading of Filipino nationwide was considered as one probable number of reasons. It was educated in all levels of learning both in public and private schools all over the country. It was utilized as the language of teaching in the academe for intellectualization and scholarly objectives. It was the connection of communication in the national tri-media which became effective tools for language dissemination. Filipino tabloids were circulated in the urban centers and local radio stations which dealt the grassroots the country and setting aside an airtime for national broadcast in Filipino from their mother stations in Manila every day (Rubrico, 2014).

In the Province of Davao de Oro, the number of speakers had been influenced by the "TagBis" (combination of Tagalog and Bisaya) dialect which was comparable to the Conyo language. Most of the speakers were the college students and the young professionals who educated themselves in colleges and universities in Davao City. The city's way of life had been dominant and manifested heavily among these people due to the proximity of the city to its neighboring cities like Tagum and Panabo who shared also the same phenomenon. In school and in working place, the use of this dialect had been trending and placed itself within the students as well as teachers who used this on a daily basis. The researcher hoped and addressed the gaps and be able to seek answers in the study through urgently conducting this study with utmost consideration that the researcher trekked in respond to the queries on the invasion of Davao "Conyo" among the students and teachers in Davao de Oro.

Purpose of the Study - The purpose of the research is to analyze Davao Conyo language as utilized by students of Mabini National High School. At this stage of research, the morpho-semantic features of the Davao Conyo language were generally defined as an analysis in order to understand the language commonly used by a number of students in Mabini National High School and be identified to it affects in the communication process.

Research questions - The study sought to answer the following questions:

$>\quad$ What are morphosemantic features of Davao Conyo as used by students in Mabini National High School? 
$>$ How do these morphosemantic features of Davao Conyo affect the communication process?

$>\quad$ What are the insights of the students in utilizing Davao Conyo in their local setting?

\subsection{Theoretical Lens}

This study was viewed from the Howard Giles' Communication Accommodation Theory (1973). He noted and emphasized the different variations in terms of the verbal communication patterns of his peers which he linked to the moving in and moving out in North Welsh pub. These observations led to significant theoretical contribution to communication theory. The core of the theory was the insight of the individual or social group which entailed about the modified communication processes which linked to perceived identity and preferences of the audience. It accommodated the listeners to convey communication process effective and operative.

In addition, there were two basic strategies of accommodation being identified namely the convergence and divergence. "Convergence is defined as a "technique in which individuals adapt to one other's communication behaviors in terms of a diverse range of linguistic-prosodic-nonverbal aspects such as speech rate, pausal phenomena and utterance length, phonological variations, smiling, gazing, and so on. "Divergence," on the other hand, is a method in which individuals "accentuate vocal and nonverbal distinctions between themselves and others". Any individual or social group will use techniques by means of moving towards or moving away from a more prestigious communication pattern to a lesser prestigious communication pattern (Giles et al., 2010). Furthermore, convergence and divergence were the main issues in Communication Accommodation Theory. The Behavior-centered Communication Accommodation Theory pertained convergence as "accommodative strategy used by individuals to identify more closely with others in the communication act.". Divergence is "used to differentiate oneself from others" (Dougherty et al., 2010).

In addition, this was supported by the Theory of Morpho-semantics which underscores that language can be described by the semantic analysis of words through their constituent morphemes. Morpho-semantics can be a useful tool in getting access to the underlying meaning of words in languages, including the Davao Conyo language used by students. This yielded significations that go beyond the surface meaning of the words contained in the languages (Dorais, 1948). This study was also gleaned in the morphology or word formation processes considered as relevant and helpful. The concept posited that systematic regularities may arise in different ways and approaches when there was morphological change in the central idea. Moreover, morphological change became special when it affects the morphology of the language. Morphological processes include compounding, clipping, initialism, acronym and affixation (Finegan, 2004).

Compounding is a word formation process based on the combination of lexical elements. These elements were categorized as words, stems or lexemes, depending on the language and on the theoretical framework adopted. Clipping refers to word formation process which consists the reduction of a comment to one of its parts. In Addition, it was not coined as words which belongs to the standard vocabulary of a language. It originated like the terms of a particular group such as exam(ination), lab(oratory), vet(eran) (Hacken, 2017). Moreover, clipping refers to the process when a multi-syllabic word was shortened by one or more of the syllables. The occurrence of shortening can be occurred at the the beginning, at the end, and can be both as well. These were some of the eamples: automobile $\rightarrow$ auto, gynaecologist $\rightarrow$ gynae, aeroplane $\rightarrow$ plane, violoncello $\rightarrow$ cello, influenza $\rightarrow$ flu. Initialism is a sequence of initials used as a word. It is also referred to a set of initials represented by a name, organization and other entity. Affixation is a word that does not have changes in form and the meaning is not always the same (Finegan, 2014). Further, the morphological processes were also adopted Murray with the following methods: affixation, compounding, initialism, acronym, clipping, and blending (Murray, 1995).

Additionally, the semantic change processes were intensified in this study of semantic change stating that the change of meaning of words and expression happened in every language all the time through semantic change process. It had been raised that when the sense of an existing word changes without simultaneous change 
of word class it is called semantic change. These changes were usually neither foreseeable nor ordered, and the cause of such a change can be found outside of language as a development in technology, society, religion and so on. The new meaning developed in these cases were usually linked in some way to the original purpose. The following processes include extension (metaphorical extension), widening and neologism. The extended extension is how words and meaning can be changed. The extension (metaphorical extension) refers to a word that gains an additional sense when it is used in new context; example, the word 'mouse' to mean the computer pointing device in addition to rodent (Yule, 2003).

Neologism refers to the newly created terms, words or phrases which maybe commonly used in everyday life. It must be formally accepted by the constituting mainstream standard of the English Language. "Neologism" came from French word Neo which means 'new', and Greek word logos, which means 'word'. Furthermore, these were directly attributed to specific person, publication, period or event. Neologism was first used in print in $\mathrm{AD}$ 1483. It was a complex term that required a deeply interpretive definition. In fact, there were various academic definitions of neologisms that were available. Then, Neologism was not a field of study on its own. Words without changes in meaning remained unchanged or zero changed process (Yule, 2003).

Lexical categorization became an integral part of words formation. Lexical categories were often referred to as "part of speech" which generally focus on content words nouns, adjectives, verbs- these are the words that contain meaning in and of themselves. (Finegan et al., 2017). Moreover, for better understanding and suitability usage of the new terms, the morphosemantic process inspired by the terms employed necessitates classification of words such as lexical category and its semantic altered processes and morphological processes. It had said that the terminology employed, particularly novel terminologies, must be subjected to morphosemantic analysis and classification in order to be valid and proper (Gratsman \& Hughes, 2017).

Lastly, this study was reinforced by discourse analysis which appealed that language can be analyzed beyond the sentences. As such, one way of exploring the speech was to examine the rage chunks of utterances as well as to consider the larger discourse context in order to understand how these affect the meaning of utterances. With the language being analyzed beyond the sentential level, language can be understood more comprehensively (Tannen, 2012).

\subsection{Significance of the Study}

The study offered and provided additional information that determines the new language of the people in attempting its influence about life process and active participation in times of natural phenomena occurrence. Specifically, the result of the study may serve as beneficial to the following:

$>$ Students benefitted this study which was significant in their experiences on the use of Davao "conyo" in daily conversation. This can increase their social responsibility and awareness on the importance of using proper dialect within the region.

$>$ More so, this study helped the Teachers in a sense that they themselves were one of the concerns in the strict implementation of using formal language especially in the classrooms.

$>$ Furthermore, the Department of Education officials established concrete implementation of the language used in classroom conversation. It gave them insights as to how the personnel especially the teachers communicate well using the appropriate medium of instruction.

$>$ Subsequently, Future Researchers gained insights in this study. Through the emergence of responses in the later part of the study, the analyzed themes aided the other researchers to discover among themselves and another study that emerged and be used in the future research. 


\section{Literature review}

\subsection{Morphosemantic Analysis}

Exploration of the form of words and their arrangement into a language's grammar was an important component of language analysis. A language satisfied the communicative requirements of the society and people using it when certain policies were observed in the creation of linguistic expressions. Lexical category is a unit of categorization of words in the grammar of a language and serves to portray the unique configuration characteristics of particular words and word classifications (Aigbedo, 2015). Furthermore, morphosemantics is a branch of linguistics that deals with morphological analysis along with semantic interpretation and categorization of words based on their lexical category and morphosemantic word modifications and structures (Khosrow, 2017). Hence, it was given meaning as the semantic analysis of words through their constituent morphemes. Morphosemantics can give a valuable resource for getting access to the underlying definition of words in polysynthetic languages, where lexemes often arose from the aggregation of numerous morphemes. This frequently results in essentials that go beyond the surface meaning of the lexeme. Morphosemantics has lately been used in computerized classification, parsing, and interpreting terminologies and scientific terminology, medical and social terminologies, and jargons in particulars (Namer \& Zweigenbaum, 2015).

Morphological Change Process - Morphological change was any altercation, addition, and deletion of one or more morpheme to a word. The morphology of English will be changed. Modifications included its function and definition of morpheme that had inflectional paradigms and derivational patterns. Similarly, English represented the grammatical functions about nouns, e.g., doer, receiver, and beneficiary. Morphological processes had changed some stems to derive new words. It altered the words from definition (derivational) or grammatical function (inflectional). Many kinds of processes were presented in all languages but not all. Examples were concatenative, its meaning involved the linear which combined by the morphemes (affixation, for example), others were non-concatenative which involved the alternation of internal properties of morphemes. Thus, morphology was the study on the ways, how words were formed. Following morphological processes were compounding, clipping, initialism, acronym and zero affixation. Compounding refers to two words combined, retaining the totality of both words. It was combined with two or more stems to get a new word which was stored in a single entry of the lexicon, e.g., 'blackbird' or 'three-year-old'. Compound was not affected by spelling. It was represented as one word as in 'housefly', hyphenated as in 'extra-terrestrial' and 'out-of-pocket', or separated by a space as in 'kill-joy'.

Compounds can be either endocentric or exocentric. Former was defined as the compound that was semantically transparent from the definition of its constituents. On the other hand, the kind of its head (as blackbird is a type of bird). While exocentric compound is not comprehended by the total of its components. For example, a 'pickpocket' which was not a pocket but somebody who picked objects from pockets. Clipping referred to a word formation processes that were comprised in the subtraction of word from one of its parts. These were not created as words which were belonged to the standard vocabulary of a language. It started as terms of a distinct cluster like exam(ination), lab(oratory) and vet(eran). Initialism was a sequence of initials utilized as a word. It was also a group of initials represented by a name, an organization, or another entity having with every letter pronounced individually as FBI for Federal Bureau of Investigation. On another hand, Zero Affixation was a word who undergoes no variations in form, in addition, the definition is not always the same.

Morphology was the study of word formation. Words were usually recognized as syntax being the smallest unit. In most language, words can be linked to other words by having rules. It was understood by the speaker in each case mirror particularly having the patterns of the words that were structured from smaller units and how those smaller units interacted in speech. Furthermore, morphology was defined as the discipline of linguistics that studies the patterns of word production across and within languages. It was attempted to explicate new formal rules of being reflective on the knowledge used by the speakers in any forms of language. The morpheme 
was smallest meaningful unit of language contained by its grammatical function (Finegan, 2018).

Furthermore, it was emphasized that morpheme can be either stand to a single basis or required to be mixed with at least one of the other morphemes to form a word. The morpheme which can stand singularly was known as a free morpheme or root. The morpheme required to be attached with another morpheme called as a bound morpheme or affixes, example: dogged, daily, foolish. The biggest source of intricacy particularly in morphology was that the one-to-one correspondence between its definition and its form. It did not apply to every situation in the language used. In English language, words that formed in pairs like ox/oxen, goose/geese and sheep/sheep had the difference between singular and the plural signaled. It was shifted from the normal pattern and in some cases, it was not signaled at all (Wilkims, 2015).

Morphological Processes - In grammar, the words were the basic units of analysis. Grammarians classified the words based from the parts of speech. It was identified and listed the forms that words shown up. The matter was very complex because it began with the assumption that were all generally able to extricate words from other linguistic units. It was an adequate for the initial purposes and the undertaken words were the main units that were used for entries in dictionaries. In other section, it was briefly described of the distinguishing characteristics. The words became potentially multifaceted units which composed of even more basic units, called morphemes. Morpheme is considered as the smallest part of a word that has grammatical purpose and meaning. Examples such as; (NB not the smallest unit of meaning); we labelled them in braces- \{\} . For example, sawed, sawn, sawing, and saws can all be analyzed into the morphemes $\{$ saw $\}+\{$-ed $\},\{-n\},\{-$ ing $\}$, and $\{-\mathrm{s}\}$, respectively. None of these last four can be further separated into evocative units. Each occurred in numerous other words, such as looked, mown, coughing, bakes (Bista, 2015). \{Saw $\}$ occurred on its own as a word which it did not have to be involved to another morpheme called as a free morpheme. However, none of the morphemes were listed just above and were free. Each must be affixed (attached) to some other unit. Then, it occurred as a part of a word. Lastly, morphemes attached as word parts were said to be guaranteed.

Affixes were classified according to where to be attached whether before or after the form. Prefixes were attached before and after the suffixes. The bound morphemes listed earlier were all suffixes. Example, the $\{\mathrm{re}-\}$ of resaw was a prefix. Being bound or free, morphemes classified as root, derivational and inflectional. In a root morpheme, the basic form to which other morphemes were attached. It provided the basic meaning of the word. On the other hand, the morpheme \{saw\} was the root of sawers. The derivational morphemes were added to form and to create distinct words: $\{$-er $\}$ was a derivational suffix whose addition goes a verb into a noun. It usually happened that the meaning of a person or thing performed the action denoted by the verb. For example, $\{$ paint $\}+\{$-er $\}$ created painter and one of the meanings was "someone who paints." (Bista, 2015).

Inflectional morphemes cannot create separate words. It merely modified words in which it has occurrence in order to indicate grammatical properties such as plurality, as the $\{-\mathrm{s}\}$ of magazines does, or past tense, as the $\{$ ed $\}$ of babecued does. English has eight inflectional morphemes. It regarded the root of a word as the morpheme left over when all the derivational and inflectional morphemes had aloof. For example, in immovability, $\{$ im- $\},\{$-abil $\}$, and $\{$-ity $\}$ were all derivational morphemes. When we remove them, we are left with \{move\}, which cannot be further divided into meaningful pieces, and the word's root (Bista, 2015). We extricated the word's root and the forms to which affixes were attached. In moveable, $\{$-able $\}$ was attached to \{move\}, which we've determined was the word's root. However, $\{\mathrm{im}-\}$ was attached to moveable, not to \{move (there is no word immove), but moveable was not a root. Expressions in the affixes were attached. It was called bases. While roots may be bases, bases were not always rooted (Bista, 2015).

Semantic Change Process - Altercations in semantics or lexical definition change was modification in the definition of words - from increase in lexical objects. Typically, semantic change was referred to a word that acquired a new definition e.g., wife from an adult female to a married female. When a new word was born or borrowed, e.g., chiffre from Arabic sifr, the word sandwich was a good example. The common noun "sandwich" had a distinct word from the proper noun "sandwich" part of the title of its associated person - Eare of 
"Sandwich" from which it derived. This derivation happened by a process called eponymy, e.g., using the name of a place or person as a common noun. The vocabulary altered quickly as new words were borrowed from other languages, words will be combined or shortened and vocabulary changed quickly. Then, syntactic change of words in a sentence altered more slowly (Lyons, 2015). Thus, variations in definition and variations in form can be internally or externally motivated. The corresponding paradigm morphology was in semantics. The word field in which words and meanings stood in a network of relationships. This modification of definition happened because the words were constantly applied and was intended by speakers. If a diverse intention for a word was shared by the speech community it was established in usage, then a semantic modification had happened (Dasher, 2015).

Traditional methods to semantic change focused on the outcome of definition change and listed several forms of variation such as metaphoric and metonymic expansions. Positive and negative meanings are being broadened and narrowed, as well as positive and negative definitions are being improved. Examples were generally considered out of context, and are lexical members of nominal and adjectival word classes (Yule, 2008). There were several kinds of changes. The most impartial method of denoting to change was speaking of semantic shift and the speak about modification. By starting a series of dresses that were designed to acquaint learners with possible realm of semantic change. The following processes were inclusive of extensions (metaphorical extension), widening and neologism. The extended extension is how the words and definitions can be altered. It pertained to a comment that gained an additional meaning when it was utilized in new context, for example, the term "mouse" to mean the computer pointing device in addition to rodent (Yule, 2008).

Morphology and Morphological Analysis - The study of words was known as morphology. Words were made up of morphemes. It had a matching meaning and could not be subdivided. In addition, the two main types were free and bound. Free morpheme happened alone and bound morpheme had occurrence to another morpheme (Wagner, 2019). Further, morphological analysis is an attempt to capture the structure of language at the level, thus its concern is on forms of word. Morphology dealt with how words categories were composed. An example of this, how a morpheme was arranged during the developmental stage of the word. A root morpheme is essential as it carries the primary meaning. It was introduced and had successfully used the process in building of reaction engines (Matthew, 2015). Morphemes were described as morphological atoms which are the ultimate elements of morphological analysis (Haspelmath, 2017). Words were composed and mixed together into more minor elements to form more significant words with more intricate meanings referred to as morphologically complex words. If how difficult lexical items were made by connection of different constituent morphemes, then analyzing any difficult word into its various constituents (Plag, 2018).

Semantics and Semantic Analysis - Semantics is a discipline in linguistics that dealt with the study of meaning, which can be definition of words, phrases or sentences. It attempted to comprehend what meaning is an element of language, how it is constructed by languages as well as how it is interpreted, obscured and dealt with by speakers and listeners of language (Merrindah, 2016). Further, it highlighted that it had scope of semantic meaning which is seen from two perspectives namely the narrow and broad sense. When it is the little sense, semantic refers to the study of importance in the lexicon alone especially from the traditional perspective. On the one hand, when it was the broad sense, it refers to importance of words and higher units in grammar such as phrases and sentences as well as word meaning changes. Additionally, semantic analysis generally dealt with definition in language (Klapuri, 2017).

The approach of linking syntactical forms, from the level of phrases, clauses, sentences, and paragraphs to the level of the text as a whole and language-independent definitions, was semantic analysis. Moreover, it involved the detaching features particular to a specific language and social context towards to the extent that such project was possible (Cliff, 2018). Similarly, semantic change pertained to the modification of the relationship between a word and a cluster of referents that a specific word may denote. Altercations in the definition conveyed by words can affect the lexemes and the morphemes, hence, there were semantic shifts in both lexical and grammatical notions (Moyano, 2019). 
Morphosemantic Properties - The meaning of a word is strongly determined by the morphemes that were linked to specific language. Some of these are predefined definitions while others vary, depending on the tongue. Morphosemantic properties relate to the study of morphology (morphemes) in relation to semantics (meaning). Further, it may also be given importance as the semantic analysis of words through their constituents' morphemes (Isguder, 2015).

Vocabulary Change in English - The central point in language development pertained enhancement and expansion of the vocabulary. The newly-created words after a certain period of time which were perceived as rare or ambiguous entered as new stocks in English vocabulary. This demonstrated that language transition and development was ongoing and consistent. Those new terms were indications of significant changes in the language, particularly in the English lexicon. It was confirmed that the inherent flexibility of human language was utilized, as well as its complexity and originality. It causes it to be highly variable and to be modified over time. Totally new verbal signs were added as newly minted word created to enter the language. These new styles came and had background in creative writing, movies, and games. A lot was patchwork creations were original can be traced to a mixture of existing word styles (Akunna \& Dent, 2015).

In modern English, vocabulary change sometimes became a problem socially. It was because some people reacted to negatively, to these modifications feeling that the language they were used to become downhill, disadvantageous and hinder communication. In today's generation, those who were frequently used social media were those who were more conversant. As further elaborated social networking sites (SNSs) such as Facebook indeed attracted millions of teenagers especially that they were born in a digital world. This hugely widened the English vocabulary. Meaning of well-known words had shifted drastically. This acted as a wake-up call for freshly created words, new phrases, or innovations of existing words or idioms. Words were the main building blocks of language. These became the standard of any altercations in the language. Vocabulary is considered as the initial idea of interaction in the development of language variation (Akunna, 2015).

\subsection{The Origins of "Conyo" Talk}

English in the Philippines had a wide range in its uses and has an extended register and style range. It also has a long history and has penetrated deeply at all levels of society (Bautista, 2004). In the Philippines existed the three circles within this Outer Circle. There was an Inner Circle of educated, elite Filipinos who had embraced the English language (whether standard American or Philippine English) which actively encouraged and protected. Another Outer Circle of Filipinos had the awareness of Philippine English as a different and valid diversity, but who were either powerless in support and hesitant about promotion. There was an Expanding Circle of users of English in the Philippines to whom the language whatever variety remained a requisite to upward mobility but had largely inaccessible (Martin, 2014). Because of stable linguistic influences brought by the results from contacts of the different peoples and cultures, a word or a phrase took another meaning among a given group of people. It differs from its original meaning, which said that "a meeting of cultures in the intercultural domain leads in irreversible intracultural alterations. The spectacle was observed among multilinguals who "develop functions of linguistic heterogeneity which go beyond the expressive possibilities available in a single code", and the translations or interpretations indicated only in figurative fate (Mey 2007 as cited by Garvida, 2012).

'Conyo' (from the Spanish coño meaning cunt) was one of the several words and phrases that had taken on new meaning in the Philippines. Aside from its unique purpose, coño was an interjection. There were several anecdotes told in the past that Spaniards used to finish the sentences. Some former Spanish colonies, coño became a synonym of Spaniard. It was exclaimed by a Chilean patron and had heard the Peninsular Spanish accent in Delibes' (1995) Diario de un emigrante: “¡Pucha, un coño! ... que había querido decir español!” (Darn, a coño! ...that he had wanted to say a Spaniard.). The distinctive Spanish exclamation had picked up by Filipinos and referred to Spaniards. It was used to signify a person who belongs to upper middle class, fair skin (that is, of Caucasian background), and was survived in an exclusive neighborhood. Indeed, it was very reminiscent of the 
colonial times. In the Philippine context, 'conyo' had no usual connection and the object was understood originally. In the previous decade, it became the solution to problems of intercommunication. Filipinos drew, knew and tailored on the languages for a specific shifting of communicative needs. 'Conyo' talk became an emulation of how English and Spanish speakers talked to native Filipinos. Lastly, it became a stance among the middle class and the preferred means of communication to others and had potential relationships (Garvida, 2012).

Conceptualizing Davao Filipino in Various Language Contact Theories - The paper entitled "The Nature of Conyo in Davao City: A Language Inquiry," defined Davao Conyo as the cross language due to the prestige and increased confidence. In Davao City, speaking the language Davao Conyo can be a basis to show the privileged status in the social order (Albino, Romo, \& Lovitos, 2016). The study thesis entitled "Davao Filipino and its Literary Possibilities," bid to theorize the mix language as a Filipino creole continuum. It was based from the analysis on Platt's three-dimensional continuum of Singlish. A creole continuum of Davao Filipino that considered 'standard Filipino' at the acrolectal level. The typical Filipino is impacted by regional language at the mesolectal level, and Davao Filipino at the basilectal level. It was extensively studied and utilized creolization that the sociolectal degree of linguistic interaction was critical in generating an inventive cultural identity or new ways of creative expression. Finally, while discussing creolization and the acrolect as the colonial language, it was underlined that the formation of a sociolectal feature of Davao Filipino be examined through a postcolonial lens (Demetrio III \& Dreisbach, 2017).

The Communication Process Using Davao Conyo - Language components changed within a certain location or region, maybe due to intercultural connections and the development of hybridity between individuals of distinct culture and language, resulting in the formation of "third space" or a way of adjustment. This resulted to another form communication that may emerge in aid and satisfaction to communicative requirements. This was main reason for the rising of Davao Conyo as an emerging dialect used. The use of this emerging dialect was framed in meme cultures which gave some impacts to the ways and its people's perspective thru Davao Conyo local speakers. The rise of the new language was ascertained to be a medium to comply for Davao's linguistic diversity and it had recently started to make itself known nationwide through social media (David, 2015). Davao Filipino/Davao Conyo in Meme-Culture" context online was perceived as the primary source of laughter and for entertainment. But, beyond that, it was unclear what the Davao Conyo, as a burgeoning colloquial language, and how it had developed in the entertainment industry, which had an influence on the language's local speakers (Dolalas, 2017). The components of language were assorted within a specific area or region maybe for the reason of intercultural connection and the existence of hybridity between individual of diverse culture and language, the production of "third space" or a method of adjustment occurs. This was resulted to another form communication that emerged in aid and satisfaction to communicative requirements. This was the main reason for the rise Davao Conyo as an emerging dialect, and how the use of this emerging dialect is framed in meme cultures which impacts the way people view Davao Conyo local speakers.

The Evolution of Davao Conyo - Conyo is generally defined as a manner of speaking that had combination of the language English, Filipino, and Bisaya in a "posh" manner. Davao Conyo, otherwise known Davao-Tagalog. Tagalog spoken as a native language in Davao and neighboring areas having significant afflictions of Cebuano. The meaning of Davao Conyo as Davao Tagalog codeswitched to English. There were variety of reasons why Davaoeños chose to speak this language. Speaking the standard Tagalog cannot be pulled off perfectly leading to resort the combining Cebuano words in the manner of speaking. There was became a trend in influencing others who do not speak in Davao Tagalog to use the same way of saying. In addition, the "social-cllimbing dimension" can be one of the reasons why people said Davao Conyo. Conyo-speaking students were labelled by most "posh" and "stylish". It had the volume and chance to express and to utter in typical Tagalog but used Davao Conyo in order to "fit in." Nonetheless, Davao Conyo sustained to embellish and to continue alive in the city and neighboring areas. It grown along with indirect policies observed in every sentence came out the mouth of every Davao Conyo speaker (David, 2015). 
The Rise of Davao Conyo and the Social Media - There was a study conducted that most people agreed to the emergence of Davao Conyo in some industries which included the entertainment industry and the social media were excellent and beneficial because of two common points. First, it diminished the people's perception of an elitist language in Davao to a more straightforward form of an entertainment and proved how dynamic language was. There was also a prejudice against conyos thinking that most, if not all, were "maarte, feeling mayaman and social climbers." Second, it offered the Davaoeños a particular identity mirroring the complexity of language made essential because of the diversity of culture in the area (Hernandez, 2018). There were point fitted and cited about the conyo talk that being a cultural identification of its speakers with linguistic backgrounds on it. The conyo speakers do not speak in such manner out of spontaneity, but instead to intentionally put boundaries around their space (Garvida, 2012).

On the other hand, some local speakers of Davao Conyo also believed that increased fame of Davao Conyo had opposing views, implications and perceptions; both to them and the language itself. A point that emerged based on study that the emergence of Davao Conyo will eventually lead to Davaoeños' losing their authentic dialect which is Cebuano or Bisaya. He further mentioned that the fusion between these languages held a risk against the survival of pure Cebuano as it allowed Tagalog to interpenetrate, that led to the decrease in people's interest for the dialect (Dolalas, 2017). Another point tackled was that Davao Conyo does not represent the Davao community as a whole, since it was just mainly evident to students especially for students who came from various places around the country with different dialects. There were Davaoeños who strongly believed that the perception towards Davao Conyo differed and relied on its utilization and the composition of the videos or memes made in social media (Hernandez, 2018).

It does not impose good or bad, it was subjective by how people perceived it and how it was presented and it was the only a new breed of identity branding to its various cultural backgrounds. This can be connected to the theory of intercultural praxis which basically shown on how to deal with communication barriers (Sorrells, 2016). This section had explored the relevant literature about the Davao Conyo language and the morphological and semantical analysis which were in respect to the morpho-semantic research. Indeed, the language had changed, altering the vocabulary in English as a result of this generation, resulting in a change in communication as well. It was presented how the words in Davao Conyo greatly diverse from what the older generations and new generations were used. In closure, this section was very vigorous and aided to the study for the reason that this brief background of the jargons and terminologies used in Davao Conyo gave the reader the initial and new basic information about the unique and pensive way that the language was being studied. Moreover, it would shed light to some of the significant questions on the inquiry of speech of that particular language.

\section{Method}

Research Design - This study utilized qualitative type of research that employed discourse analysis. Qualitative methods, as the name indicated, was concerned with inquiring about specific phenomenon or event, individual's behavior, culture, practice sand values, beliefs and perceptions. This data was described and reported generally in textual form (Amorado \& Talili, 2017). In this study, qualitative design was used for the exploration of the Davao Conyo manner of speaking. Hence, it did not need for the utilization of survey nor data that involved numbers or Statistics. Moreover, discourse analysis was the study of language used and was part overlapped the pragmatics. This was how sentences, the most complex units within the language system were out to be used and to be combined with one other used as utterances. The utterances made do not come as an isolation sentence, but had used the longer stretches of language to the text and its discourse. The discourse was used to all units of speech (even if lesson over more extended stretches of time, such as a political or scientific discourse relating to one topic), and integration of aspects of the situations and sociocultural context utterances (Dorgeloh, 2009). Thus, this type of design used was to discover the richness of the language of Davao Conyo. Furthermore, discourse analysis was given appropriateness and accuracy because it dealt with studying the language of Davao Conyo, and morpho-semantic analysis because this study analyzed the morpho-semantic features of Davao Conyo, specifically on its word-formation and meaning, as well as the effects of the 
communication process.

Research Participants - Fourteen (14) junior high school students of Mabini National High School in the Division of Davao de Oro were the participants of the study wherein seven (7) had undergone in-depth interviews and (7) had undergone the focused-group discussion. They were chosen because of their exposure to the use of Davao Conyo which I thought it was enough for them to express their own thoughts and various perceptions with regards to the information needed from them. This was also the main reason why the study had no gatekeeper that gave connection to the researcher to the informants through the language barrier. The seven participants had undergone in-depth interview (IDI) while the other seven participants had undergone focus group discussion (FGD) (Creswell, 2014).

Inclusion of criteria of the participants were set within the bounds of the study. First, participants were selected accordingly on the merits that they were influenced by the Davao Conyo way of speaking. Second, Grade 10 students of Mabini National High School. Third, they were using Davao Conyo in their daily communication and interaction with other people in school. Third criterion was met by asking other students as well as the teachers to pinpoint students who were really using the Davao Conyo language in their daily interaction.

Exclusion criteria were also set within the bounds of the study like they were not engaged and immersed in using the language. Also, it excluded that the students who were not from Mabini National High School and those that were not exposed to the language of Davao Conyo and were not utilized it in speaking and interacting with other people. Moreover, purposive sampling method was used. It was widely used and became popular in qualitative research in order to identify and to select an information related to the phenomenon being studied. Purposive sampling is described by the use of particular requirements that participants must meet at the time of selection. As a result, the participants were carefully chosen based on the inclusion and exclusion criteria (Palinkas, 2015).

Data Sources - The source of data was gathered in multiple forms such as interviews, observation, and documentation. Discussions had an open-ended question to be asked with backers, service providers and the participants. There were website hits, audio recorded and visual methods included photos (Creswell et al., 2007). In this endeavor, the sources of data came from the Junior High School who were used and had spoken Davao Conyo. They were my primary source of data as I was studying the language that they used. The acceptable criterion for this were 14 students in each learning episode, composed of a diverse student consisting of teens whose age bracket was not less than 14 but not more than 16 years old.

Data Collection - In obtaining the data relevant to this study, I organized and followed a step-by-step procedure. Qualitative researchers undergone sequence of activities to the process of gathering the data before reaping the completion of the research study (Creswell, 2007). As a researcher, the thing I did was to secure the approved validation sheet from the expert validators. Since the study was about a school-based occurrence, I secured an endorsement letter from the Dean of the Graduate School prior to sending of letters to the authorities. I sent a permission letter requesting to conduct the study to the Office of the Schools Division Superintendent of the Division of Davao de Oro for the approval. Another letter was sent to the school principal of Mabini National High School for the permission to utilize the selected students to be the research participants.

When the participants already known, they were informed about the study. The participants signed the consent in a form of agreement to guarantee their full participation in the conduct of the study. Because the participants in this study were under the age of eighteen (18), the researcher obtained the approval of the individuals' parents. I informed the participants regarding the objectives of this study and the entire methodology in gathering the needed data. After securing permission, I personally conducted the interview to the junior high school students. Focused-group discussions were becoming popular because it was easier to recruit to be more comfortable to the participants. I told the participants signed the consent form. Prior to the signing of the consent form, I ensured validity and credibility of my interview and secured a good Interview Guide validated by the 
Mojica, D. R. S., \& De Leon, M. G. M.

expert validators (Evmorfopoulou, 2007).

The following procedure was I conducted individual virtual in-depth interviews and focused- group discussion to students. Schedules of the interviews were set according to the availability of the informants and time must not have been exceeded in an hour. Before each individual interview, I reminded the participants about the necessary preparation. I also re-oriented them on how the interview will be conducted which made them feel at ease before the interview started. I used the interview guide in the course of the in-depth interviews and focus group discussion. I made the interview semi-structured as it allowed the participants to provide accurate and consistent information that was important to them and to understand the details of their experience from their point of view (Wengraf, 2001). Moreover, the responses of the participants had been recorded in verbatim using the audio-recorder, while taking some notes in getting some key points shared by the participants and to avoid misleading data. Significantly, I asked follow-up questions relevant to the topic for the enrichment of the information. The word-for-word conversation were transcribed; and all information gathered had been transferred and stored to the password protected folder having a password protected computer assurance in the safety of the data and the material copies stored in the locked cabinet. When the transcription was done, thematic analysis followed. In transcribing their responses, I was assisted by a friend who was also my colleague to do the note-taking procedures while the interview was in progress.

Data Analysis - In my study, the data collected and gathered in this research were transcribed into written form. Upon ensuring the validity and credibility of this study, I provided sufficient documentation that illustrated the actual proceedings of this research. I employed peer debriefing in my research and tapped experts in applied linguistics as my peer debriefer. Qualitative research data analysis was the process of analytically searching and arranging the interview transcripts, observation notes and other non-textual materials used by the researcher in the accumulation of increased understanding on the use of language (Patton, 2006). In this study, after transcribing the recorded research materials, data were treated through discourse analysis. Discourse analysis were used as the language samples beyond the sentential level. Hence, the context considered to unearth the underlying meaning of sentences of the analyzed utterances (Tannen, 2012).

In this study, analysis was used to know the terminologies in Davao Conyo as well as the meaning beyond the utterances. Aside from that, linguistic frame analysis was used to focus the study of the context of the statements. It was because one cannot understand a single word of a language without all the essential knowledge that related to the same word. Hence, frames were utilized in the study to induce a picture of what utterances said that were beyond the surface level (Willens, 1997). Lastly, this study utilized morpho-semantic analysis which was the identification of words and meaning that were inherited to the language. This also dealt with word formation processes and as to how these processes affected the importance of the words (Agbedo, 2000). The new coined words and terminologies can be easily understood by analyzing the morphological and semantic processes and lexical categorization. Since this study dealt with the vocabularies presented in the language using Davao Conyo, it was also best for the researcher to include this in her line of analytical tools (Finegan, 2018).

\section{Results}

RQ1: Morphosemantic features of Davao Conyo as used by students in Mabini National High School. Based on the data gathered from the audio recorder, there were some terminologies that were organized from the answers of the students. These terminologies had variations from the terms typically used in the Bisaya or Cebuano language spoken by other students. The Davao Conyo language used by the students have particular morphosemantic features including the morphological process and semantic change process it had undergone. The Communication Theory of Terminologies emphasized that terminologies were meaningless in themselves, unless these were used on actual discourses. In terms of morphological processes, the morphosemantic features of the language based on participant usage were evaluated and found to have experienced affixation, prefixation, and neologism. Whereas for the semantic change process, broadening and metaphorical extension were 
observed.

\section{Table 1}

The Morphology of Davao Conyo Used by Students

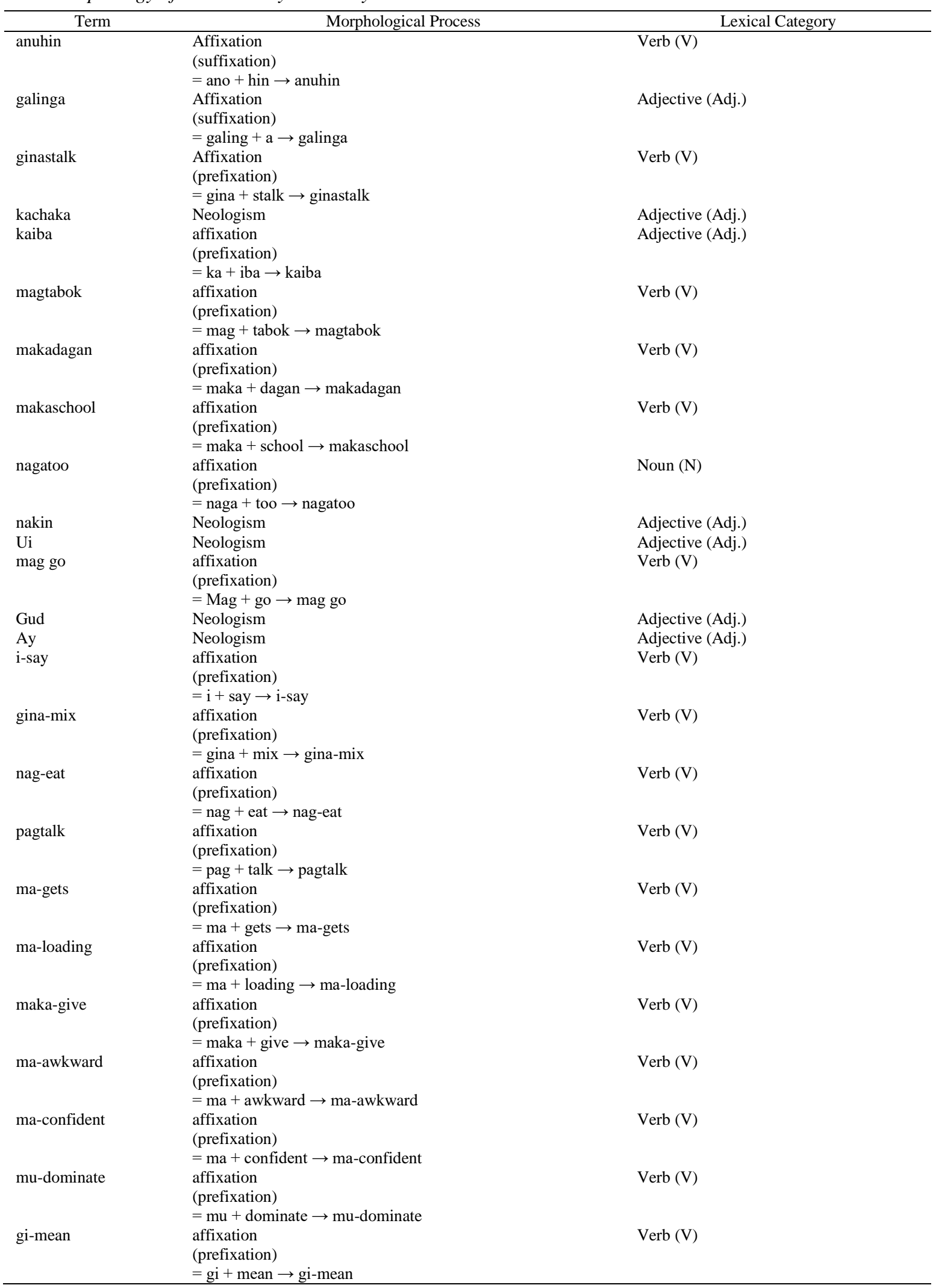


Mojica, D. R. S., \& De Leon, M. G. M.

Table 2

The Semantics of Davao Conyo Language as Used by the Students

\begin{tabular}{|c|c|c|c|}
\hline \multirow[b]{2}{*}{ Term } & \multicolumn{3}{|c|}{ Semantic Change Process } \\
\hline & Meaning Change Process & Dictionary & $\begin{array}{c}\text { Contextual Davao Conyo } \\
\text { Meaning }\end{array}$ \\
\hline anuhin & Broadening & To do something with & $\begin{array}{l}\text { It is to perform an action to } \\
\text { something or someone }\end{array}$ \\
\hline galinga & Broadening & $\begin{array}{l}\text { Make something very good; } \\
\text { Perform an act with great skill }\end{array}$ & $\begin{array}{l}\text { It means performing greatly } \\
\text { in a specific field or sport }\end{array}$ \\
\hline ginastalk & N/A & N/A & $\begin{array}{l}\text { This means the act of } \\
\text { following or pursuing } \\
\text { someone }\end{array}$ \\
\hline kachaka & N/A & N/A & $\begin{array}{l}\text { This means extreme level of } \\
\text { ugliness }\end{array}$ \\
\hline Kaiba & Broadening & $\begin{array}{l}\text { singular; strange; nondescript; } \\
\text { odd; queer }\end{array}$ & $\begin{array}{l}\text { It means being different from } \\
\text { others or from most people }\end{array}$ \\
\hline magtabok & N/A & N/A & $\begin{array}{l}\text { It refers to the act of crossing } \\
\text { the road, bridge, etc. }\end{array}$ \\
\hline makadagan & N/A & N/A & $\begin{array}{l}\text { This refers to the act of } \\
\text { running }\end{array}$ \\
\hline makaschool & N/A & N/A & $\begin{array}{l}\text { This means the ability to go } \\
\text { to school }\end{array}$ \\
\hline nagatoo & N/A & N/A & $\begin{array}{l}\text { It means believing in } \\
\text { something or someone }\end{array}$ \\
\hline Nakin & Metaphorical extension & It seems to me & $\begin{array}{l}\text { It refers to claiming a } \\
\text { possession of a thing or } \\
\text { person }\end{array}$ \\
\hline $\mathrm{Ui}$ & N/A & N/A & $\begin{array}{l}\text { This is just an addition to a } \\
\text { sentence }\end{array}$ \\
\hline mag go & N/A & to proceed & $\begin{array}{l}\text { This refers to the process of } \\
\text { continuing an action }\end{array}$ \\
\hline Gud & N/A & N/A & $\begin{array}{l}\text { This is just an addition to a } \\
\text { sentence }\end{array}$ \\
\hline Ay & N/A & N/A & $\begin{array}{l}\text { This is just an addition to a } \\
\text { sentence }\end{array}$ \\
\hline i-say & N/A & to utter & $\begin{array}{l}\text { It means having to pronounce } \\
\text { or talk }\end{array}$ \\
\hline gina-mix & N/A & to incorporate & $\begin{array}{l}\text { This refers to the process of } \\
\text { integration }\end{array}$ \\
\hline nag-eat & N/A & to put food in the mouth & $\begin{array}{l}\text { This means the process of } \\
\text { consuming food }\end{array}$ \\
\hline pagtalk & N/A & the process of speaking & $\begin{array}{l}\text { This refers to the process of } \\
\text { interaction with the use of } \\
\text { words }\end{array}$ \\
\hline ma-gets & N/A & to understand & $\begin{array}{l}\text { This means being able to } \\
\text { comprehend the words } \\
\text { spoken }\end{array}$ \\
\hline ma-loading & Metaphorical extension & $\begin{array}{l}\text { to have difficulty in } \\
\text { understanding }\end{array}$ & $\begin{array}{l}\text { This refers to not being able } \\
\text { to comprehend immediately }\end{array}$ \\
\hline maka-give & N/A & to provide & $\begin{array}{l}\text { This refers to the process of } \\
\text { giving or providing }\end{array}$ \\
\hline ma-awkward & Metaphorical extension & $\begin{array}{l}\text { to be in an uncomfortable } \\
\text { situation }\end{array}$ & $\begin{array}{l}\text { This means being put in an } \\
\text { uncomfortable situation }\end{array}$ \\
\hline ma-confident & Metaphorical extension & to have confidence & $\begin{array}{l}\text { This pertains to having } \\
\text { confidence }\end{array}$ \\
\hline mu-dominate & Metaphorical extension & to have dominance & $\begin{array}{l}\text { This pertains to being } \\
\text { dominant or superior }\end{array}$ \\
\hline gi-mean & N/A & giving definition & $\begin{array}{l}\text { This refers to giving } \\
\text { definition to the action of a } \\
\text { person }\end{array}$ \\
\hline
\end{tabular}

Table 1 displayed the morphology of Davao Conyo used by students which comprises of the term, the lexical category and the morphological process it entailed. This table showed morphological process including affixation, suffixation, prefixation and neologism. Table 2, on the other hand, presented the semantic of Davao Conyo language as used by the students. It included the terms, the meaning change process, the definition forms the dictionary and the contextual Davao Conyo meaning. In this table, it was made visible on how broadening and metaphorical extension was widely-utilized. 
Davao Conyo invasion: A morpho-semantic analysis

Table 3

The Morpho-semantic Features of Davao Conyo Used by Students

\begin{tabular}{|c|c|c|c|c|}
\hline Term & Lexical Category & $\begin{array}{l}\text { Morphological Process } \\
\text { (Murray, 1995) }\end{array}$ & $\begin{array}{c}\text { Semantic Change } \\
\text { Process (Hughes and } \\
\text { Gartsman, 2007) } \\
\end{array}$ & $\begin{array}{c}\text { Contextual Davao Conyo } \\
\text { Meaning }\end{array}$ \\
\hline anuhin & Verb (V) & $\begin{array}{l}\text { affixation } \\
\text { (suffixation) } \\
=\text { ano }+ \text { hin } \rightarrow \text { anuhin }\end{array}$ & Broadening & $\begin{array}{l}\text { It is to perform an action to } \\
\text { something or someone }\end{array}$ \\
\hline galinga & Adjective (Adj.) & $\begin{array}{l}\text { affixation } \\
\text { (suffixation) } \\
=\text { galing }+\mathrm{a} \rightarrow \text { galinga }\end{array}$ & Broadening & $\begin{array}{l}\text { It means performing } \\
\text { greatly in a specific field or } \\
\text { sport }\end{array}$ \\
\hline ginastalk & Verb (V) & $\begin{array}{l}\text { affixation } \\
(\text { prefixation) } \\
=\text { gina }+ \text { stalk } \rightarrow \text { ginastalk }\end{array}$ & N/A & $\begin{array}{l}\text { This means the act of } \\
\text { following or pursuing } \\
\text { someone }\end{array}$ \\
\hline kachaka & Adjective (Adj.) & Neologism & N/A & $\begin{array}{l}\text { This means extreme level } \\
\text { of ugliness }\end{array}$ \\
\hline Kaiba & Adjective (Adj.) & $\begin{array}{l}\text { affixation } \\
\text { (prefixation) } \\
=\mathrm{ka}+\mathrm{iba} \rightarrow \text { kaiba }\end{array}$ & Broadening & $\begin{array}{l}\text { It means being different } \\
\text { from others or from most } \\
\text { people }\end{array}$ \\
\hline magtabok & Verb (V) & $\begin{array}{l}\text { affixation } \\
\text { (prefixation) } \\
=\text { mag }+ \text { tabok } \rightarrow \text { magtabok }\end{array}$ & N/A & $\begin{array}{l}\text { It refers to the act of } \\
\text { crossing the road, bridge, } \\
\text { etc. }\end{array}$ \\
\hline makadagan & Verb (V) & $\begin{array}{l}\text { affixation } \\
(\text { prefixation) } \\
=\text { maka }+ \text { dagan } \rightarrow \text { makadagan }\end{array}$ & N/A & $\begin{array}{l}\text { This refers to the act of } \\
\text { running }\end{array}$ \\
\hline makaschool & Verb (V) & $\begin{array}{l}\text { affixation } \\
=\underset{\text { maka }}{\text { makaschool }}\end{array}$ & N/A & $\begin{array}{l}\text { This means the ability to } \\
\text { go to school }\end{array}$ \\
\hline nagatoo & Noun $(\mathrm{N})$ & $\begin{array}{l}\text { affixation } \\
(\text { prefixation }) \\
=\text { naga }+ \text { too } \rightarrow \text { nagatoo }\end{array}$ & N/A & $\begin{array}{l}\text { It means believing in } \\
\text { something or someone }\end{array}$ \\
\hline nakin & Adjective (Adj.) & Neologism & Metaphorical extension & $\begin{array}{l}\text { It refers to claiming a } \\
\text { possession of a thing or } \\
\text { person }\end{array}$ \\
\hline $\mathrm{Ui}$ & Adjective (Adj.) & Neologism & N/A & $\begin{array}{l}\text { This is just an addition to a } \\
\text { sentence }\end{array}$ \\
\hline mag go & Verb (V) & $\begin{array}{l}\text { affixation } \\
\text { (prefixation) } \\
=\text { Mag }+ \text { go } \rightarrow \text { mag go }\end{array}$ & N/A & $\begin{array}{l}\text { This refers to the process } \\
\text { of continuing an action }\end{array}$ \\
\hline Gud & Adjective (Adj.) & Neologism & N/A & $\begin{array}{l}\text { This is just an addition to a } \\
\text { sentence }\end{array}$ \\
\hline Ay & Adjective (Adj.) & Neologism & N/A & $\begin{array}{l}\text { This is just an addition to a } \\
\text { sentence }\end{array}$ \\
\hline i-say & Verb (V) & $\begin{array}{l}\text { affixation } \\
\text { (prefixation) } \\
=\mathrm{i}+\text { say } \rightarrow \mathrm{i} \text {-say }\end{array}$ & N/A & $\begin{array}{l}\text { It means having to } \\
\text { pronounce or talk }\end{array}$ \\
\hline gina-mix & Verb (V) & $\begin{array}{l}\text { affixation } \\
\text { (prefixation) } \\
=\text { gina }+ \text { mix } \rightarrow \text { gina-mix }\end{array}$ & N/A & $\begin{array}{l}\text { This refers to the process } \\
\text { of integration }\end{array}$ \\
\hline nag-eat & Verb $(\mathrm{V})$ & $\begin{array}{l}\text { affixation } \\
(\text { prefixation) } \\
=\text { nag }+ \text { eat } \rightarrow \text { nag-eat }\end{array}$ & N/A & $\begin{array}{l}\text { This means the process of } \\
\text { consuming food }\end{array}$ \\
\hline pagtalk & Verb (V) & $\begin{array}{l}\text { affixation } \\
(\text { prefixation }) \\
=\text { pag }+ \text { talk } \rightarrow \text { pagtalk }\end{array}$ & N/A & $\begin{array}{l}\text { This refers to the process } \\
\text { of interaction with the use } \\
\text { of words }\end{array}$ \\
\hline ma-gets & Verb (V) & $\begin{array}{l}\text { Affixation } \\
(\text { prefixation }) \\
=\text { ma }+ \text { gets } \rightarrow \text { ma-gets }\end{array}$ & N/A & $\begin{array}{l}\text { This means being able to } \\
\text { comprehend the words } \\
\text { spoken }\end{array}$ \\
\hline ma-loading & Verb (V) & $\begin{array}{l}\text { Affixation } \\
(\text { prefixation) } \\
=\text { ma }+ \text { laoding } \rightarrow \text { ma-loading }\end{array}$ & Metaphorical extension & $\begin{array}{l}\text { This refers to not being } \\
\text { able to comprehend } \\
\text { immediately }\end{array}$ \\
\hline maka-give & Verb (V) & $\begin{array}{l}\text { Affixation } \\
\text { (prefixation) } \\
=\text { maka }+ \text { give } \rightarrow \text { maka-give }\end{array}$ & N/A & $\begin{array}{l}\text { This refers to the process } \\
\text { of giving or providing }\end{array}$ \\
\hline ma-awkward & Verb (V) & $\begin{array}{l}\text { Affixation } \\
\text { (prefixation) }\end{array}$ & Metaphorical extension & $\begin{array}{l}\text { This means being put in an } \\
\text { uncomfortable situation }\end{array}$ \\
\hline ma-confident & Verb (V) & $\begin{array}{l}=\text { ma }+ \text { awkward } \rightarrow \\
\text { ma-awkward } \\
\text { Affixation } \\
\text { (prefixation) }\end{array}$ & Metaphorical extension & $\begin{array}{l}\text { This pertains to having } \\
\text { confidence }\end{array}$ \\
\hline mu-dominate & Verb (V) & $\begin{array}{l}=\text { ma }+ \text { confident } \rightarrow \\
\text { ma-confident } \\
\text { Affixation } \\
\text { (prefixation) }\end{array}$ & Metaphorical extension & $\begin{array}{l}\text { This pertains to being } \\
\text { dominant or superior }\end{array}$ \\
\hline
\end{tabular}


Mojica, D. R. S., \& De Leon, M. G. M.

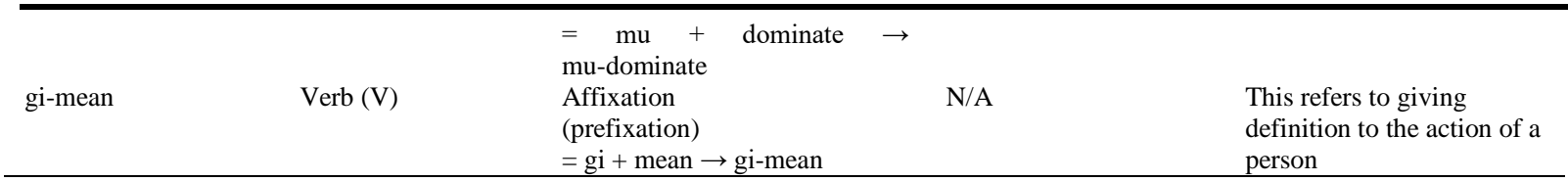

Table 3 showed the morphosemantic features of Davao Conyo used by the students which were based also on tables 1 and 2. This table was comprised of the term, the lexical category, the morphological process it had undergone based on Murray (1995), the semantic change process based on Hughes and Gartsman (2007) and the contextual Davao Conyo meaning.

RQ2: Morphosemantic features of Davao Conyo affect the communication process. Table 4 displayed the themes that emerged based on the question on how the morphosemantic features of Davao Conyo affected the communication process as well as the responses of the participants that were supported these themes.

\section{Table 4}

Impacts of Morphosemantic Features of Davao Conyo to the Communication Process

\begin{tabular}{ll}
\hline \multicolumn{1}{c}{ Themes } & \multicolumn{1}{c}{ Coded Responses } \\
\hline $\begin{array}{l}\text { Speakers Combine Two Languages to Form a Conyo } \\
\text { Conversation }\end{array}$ & $\begin{array}{l}\text { To make it into Conyo, words were only mixed together. } \\
\text { Formulation of Conyo was easy. You just mix Visaya, English } \\
\text { and Tagalog, that's it. } \\
\text { It's easy to talk in Conyo. Just mix English and Tagalog, } \\
\text { sometimes VIsaya too. }\end{array}$ \\
$\begin{array}{ll}\text { It is quite class to hear. } \\
\text { Conyo is pleasant to hear. } \\
\text { Conyo is classier to hear. }\end{array}$ \\
$\begin{array}{l}\text { Sender and Receiver in Communication Process Easily } \\
\text { Understand and Comprehend the Message in Conyo Language }\end{array}$
\end{tabular}

Even though it is not a formal speaking, one should be organized in speaking Davao-Conyo. Though confusing sometimes but it is understood if is spoken in a good way. Sometimes I quite catch up the words but if is talked slowly, I understand.

Davao-Conyo is confusing sometimes but if you speak it in good way and knew how to use English and Tagalog terms, perhaps you can easily understand. It is also considered that as a speaker, you should be organized in speaking for clarity purposes. To facilitate smooth conversation in talking Davao-Conyo, the important thing is that it should be organized in talking so as not to commit miscommunication.

You can the language during gatherings among youth ma'am. We can express ourselves if we use Conyo.

If we talked about secrets and only for us, we used Conyo but we shifted to ordinary way of talking if we were in class otherwise our teacher will get mad at us.

It can be used during bonding with friends; and Conyo was used by us.

Conyo is dominated in our generations especially in these modern times.

Conyo had been heard and spoken among the youth nowadays and we can relate to it. I don't know with the others if they can understand.

In all aspects of speaking, we used Conyo since we were the new generations.

Sender and Receiver in Communication Process Easily Understand and Comprehend the Message in Conyo Language
It's easy to understand Conyo because we knew the meaning of the words we uttered. It was easy for us to get the meaning, be it positive or negative.

It's easy to understand he/she was talking that's why the meaning was easy to comprehend.

The meaning of the Conyo words that we are talking is understood by those who talked in it. The meaning is established already though some new trends emerged.

It's easy to understand the meaning using Davao-Conyo. The meaning was easily get if the two of you understand with each other. 
After analyzing the responses of the participants about their use of the Davao Conyo language, as well as the morphosemantic features of the language, three themes had emerged on how the morphosemantic features of the Davao Conyo language affected the communication process. The following were the three themes that emerged: (1) Speakers Combine Two Languages to Form a Conyo Conversation, (2) Conversants in Conyo were Good to Hear, and (3) Sender and Receiver in Communication Process Easily Understood and Comprehended the Message in Conyo Language.

\section{Speakers Combine Two Languages to Form a Conyo Conversation}

The first theme for grand tour to express on how the participants mix two languages in order to come up with a conversation in Conyo form. Most of the participants shared that they typically combine the English language with Tagalog language or Tagalog language were combined with the local language which was

Cebuano. This theme was supported by the shared responses of the participants below:

Gina-mix lang po ang mga words para naay ginatawag nga conyo. IDI 1

(To make it into Conyo, words are only mixed together.)

A response shared by another participant was:

We combine lang the English, Tagalog ug Bisaya aron conyo paminawon. IDI3

(We only combined English, Tagalog and Visaya to make it Conyo.)

A similar response was expressed by a particular participant and stated that:

Dali ra man i-formulate ang conyo. Isagol lang jud nimo ang Bisaya, English ug Tagalog. That's

it. IDI 6

(Formulation of Conyo is easy. You just mix Visaya, English and Tagalog, that's it.)

IDI 7 also verbalized his thoughts that is related to this theme:

Dali raman magsulti ug conyo. I-mix lang nimo ang words nga English ug Tagalog, usahay bisaya pud. IDI 7

(It's easy to talk in Conyo. Just mix English and Tagalog, sometimes VIsaya too.)

This theme highlighted how creative student participants became great in the formation of conversation be considered as a Conyo conversation.

\section{Conversants in Conyo were Good to Hear}

The second theme for grand tour highlighted the appreciation of the participants in listening to people having Conyo conversation which was possibly the reason that enticed them to utilize the language. One participant shared:

For example, if we say, "nagkaon naka?" to make it conyo, we say "nag-eat na you?" medyo sosyal paminawon (laughing). IDI 2

(For example, if we say "Nagkaon Naka?", in Conyo we say "Nag-eat na you?". It is quite class to hear.)

Another participant shared that:

Gina-sagol sagol ang mga English, Tagalog ug Bisaya para pud naa mi sariling storya kay nice man gud paminawon if mag-conyo. IDI 4 
Mojica, D. R. S., \& De Leon, M. G. M.

(English, Tagalog and Visaya were mixed to have our own way of speaking because Conyo is pleasant to hear.)

It was also agreed upon by another participant:

For me, para conyo paminawon, simply i-halo nimo ang English ug Tagalog aron class dunggon. IDI 5

(For me, to make it Conyo, you just simply mix the English and Tagalog to make it class to hear.)

This theme made it apparently that students were typically influenced by what they felt especially the sounds were good to hear and made them decide to imitate and to utilize it as a language.

\section{Another Way of Teens' Expression and Conversation}

The third theme for grand tour talked about the language as the trend among the younger generations. The widespread popularity of Davao-Conyo reaches even to its neighboring provinces. College students as well as high school students can be heard frequently in different places, thus others adopted the way of speaking beyond rules in language. The responses of the participants supported the statement above.

Maskin pa ug dili siya formal speaking, need gihapon nga organized jud ang pag-Davao Conyo. Maka-confuse usahay but masabtan man if tarong lang jud pagkasulti. Usahay dili kayo nako ma-gets pero kung i-talk ug hinay, makasabot pud usahay ma-loading lang ko. IDI 3

(Eventhough it was not a formal speaking; one should be organized in speaking Davao-Conyo. Though confusing sometimes but it was understood if it was spoken in a good way. Sometimes I quietly caught up the words but if ws talked slowly, I understood.)

Another response came from the participants on the theme which were shown below:

Ang Davao-Conyo usahay maka-loading siya. Kung imong tarungon lang ang paggamit sa mga terms sa English ug Tagalog, makasabot dayon ka. Sa-pagtalk need jud ang understanding and ikaw nga speaker, dapat arrange pud ka mustroya kay aron clear kayo imo gusto isulti. IDI 4

(Davao-Conyo is confusing sometimes but if you speak it in good way and knew how to use English and Tagalog terms, perhaps you can easily understand. It is also considered that as a speaker, you should be organized in speaking for clarity purposes.)

Similar view was apparent to the participant who mentioned that they talked Davao-conyo among their circle of friends but ceased to speak if the class occurred. This was manifested in his words stressed:

Kanang mag-istorya mi if naa mi mga secrets ug mga talks nga need ug kami kami ra makabalo, mag-conyo mi then kanang the usual namo nga talk sa room pero if tingklase, dili mi mugamit ug conyo asin masuko amo teacher. IDI 5

(If we talked about secrets and only for us, we use Conyo but we shifted to ordinary way of talking if we were in class otherwise our teacher will get mad at us.)

Another participant added,

Sa mga storya sa mga batan-on paraha sa amoa, ang Conyo jud ang madunggan pirmi kay murag kami kami ra man makarelate ani maam. ambot lang pud sa uban if makasabot sila. FGD 5

(Conyo had been heard and spoken among the youth nowadays and we can relate to it. I don't know with the others if they can understand.)

254 Consortia Academia Publishing (A partner of Network of Professional Researchers and Educators) 
Furthermore, one of the participants informed:

Pwede ra gud unta nga pure bisaya ang gamiton namo Maam pero usahay dili jud namo malikayan nga maka-conyo jud mi kay we share the same feelings and gusto mao nang mu-dominate jud siya as conversation namo. FGD 6

(It was permissible to use pure Visaya but it was inevitable that we can talk Conyo since we shared the same feeling that's why it was dominated much in our conversation.)

As trending nowadays, the language incorporated among the new generations had been rapidly influenced their minds. Subsequently, it gave us an understanding on how this language dominated in such a way that it was heavily influenced the communication skills in a positive and negative aspect.

\section{Sender and Receiver in Communication Process Easily Understand and Comprehend the Message in Conyo Language}

The fifth theme for grand tour two manifested the way how communication flows used this language. Since Davao-Conyo reached its sphere of influence among the youth, the style of communication skills was quietly changing. It requires a precise grasp of the words so that it reaches the receiver's ears in a comprehensive manner; otherwise, misunderstanding occurs.

Sa akong experience, at first, mailang ko basin mamali ko pero nagkadugay maanad naka Maam. Mao nang ang meaning sa mga conyo words ok ra kayo kay masabtan dayon. IDI 3

(At first, I am hesitant but as time goes by, it's easy for me to understand.)

According to the response of the participant, she stressed that,

Ma-gets niya ako gisulti, ma-gets pud nako iya gisulti, mao nang ang meaning easy ra sabton Maam. IDI 5

(it's easy to understand he/she was talking that's why the meaning was easy to comprehend.)

In the same vein, another response from one of the participants added that:

Ang meaning sa conyo words nga ginasulti namo Maam kay kuan...kanang masabtan sa mga nagsulti pud ani unya establish na ang meaning maski naay mga new nga trends sa pagsulti. IDI 6

(The meaning of the Conyo words that we were talking was understood by those who talked in it. The meaning was established already though some new trends emerged.)

To continue, one of the participants elaborated the though mentioned above:

It is easy ra masabtan ang meaning kung magtalk ka using Davao-conyo. Mas dali ra makuha ang meaning kung kamo nga nagtalk nagkasinabot. FGD 2

(It's easy to understand the meaning using Davao-Conyo. The meaning was easily get if the two of you understand with each other.)

RQ3: Insights of the Students in Using Davao Conyo in Their Local Setting - Using Davao-Conyo was phenomenal. Like any other languages naturally spoken in all parts of the world, this language also connects and facilitates communication especially to those individuals or groups who has the same point of views like that of the youth nowadays. The new generation adopted the globalization and as part also of their trend which others cannot conform to them, they developed these spoken words to look unique among the many. However, it could be noted that the essence of learning formal language was being left out or declined. This arising problem 
Mojica, D. R. S., \& De Leon, M. G. M.

especially in writing and constructing composition truly affected their way of learning.

Table 7 presented the themes and core ideas on the students' insights in using Davao-Conyo in local setting. On the process of data analysis, the following themes emerged: establish bond and companionship, language incompetence, loss of self-esteem, bridge connection and language without rules and standards.

\section{Table 5}

Major Themes and Coded Responses of Participants on their Insights in Using Davao Conyo in local Setting

\section{Major Themes}

Establish Bond and Relationship

Challenging to Learn the Conyo Language

Negative Comments are Unsuitable for a Conyo Speaker

Freedom in the Use of Conyo Language is an Experience

Grammatical Rules are not Necessary in Conyo Language/Conversation

Grammatical Rules are not Necessary in Conyo Language/Conversation
For us new generations, it is important for us to establish bonding with each other.

It is important since it helps us to connect with our friends and I feel comfortable to talk to my friend using Conyo.

Sometimes, older generations tend to irk at us, sometimes they say that we pretended to be rich upon using Davao-Conyo. It is trending in the youth among us which is important.

Though others might hear it negatively, I can say that it is important in some ways because it creates bonding and friendship as well as having same thoughts and ideas.

It is important in a way that it gives strong bond in terms of relationship among friends. Because of Davao-Conyo, I developed friendship and closeness.

I struggled sometimes especially if I am not well-versed. At first, I had difficulty and I hardly understand since I'm on process of learning Conyo.

Sometimes I find it difficult to comprehend when your friend is fast in talking Conyo. I cannot easily get the meaning of what he's talking.

I find it difficult in pronouncing sometimes the placemtn of the words if I'll use English or Tagalog. It made me confused because it will not be Conyo if it is in pure Tagalog. At first, it is really challenging to learn Conyo. My sister always talked in home until I learned how to talk conyo also but I had difficulties especially when you talked to fluent Conyo speaker. I realized that if you talk to your friends using Davao-Conyo, no negative feelings towards them because you understand with each other.

It's easy to your fellow who knew Conyo. However, it's difficult for others and they might be intimidated or mad but to those who knew it, it's okay.

I realized that it really helped although Davao-Conyo is a mixed word, it built confidence and I feel that I'm good in English, I felt proud in it and talked with confidence.

Davao-Conyo makes one develop his/her skill in speaking.

Since English and Tagalog is always uttered, it helps to develop your speech.

considered Davao-Conyo important because through this, you can express your feelings especially when posting to social media.

You have the freedom to make your own version of Tagalog, Bisaya and English Ma'am and you can also mix words as long as it is understandable.

In Davao Conyo language, the rule is that as long as you can mix three languages, it is okay as long as you deliver it properly. It may sound weird but just go on with it since it is still understandable.

Although it's not formal or recognized as language,

Davao-Conyo is important especially in using English because before, I cannot express myself in pure English.

Communication can improve a little but not almost perfect. My realization is that it is helpful in speaking.

Since Davao Conyo language is informal, the words being used are also informal. It really affects how you use the words constantly and how to decide.

\section{Establish Bond and Companionship}

The first theme showed the ability of the language to establish bond among people who spoke the language. The impact of establishing bonds among the speakers had been observed as an effective tool for communication 
process. The tongue acts as binder to those who used it. Responses below have shown:

Para sa among new generations, important siya kay through ani, ma-establish namo ang bonding with each other. IDI 1

(For us new generations, it is important for us to establish bonding with each other.)

In addition, another response from the participant is manifested pertaining to the theme. He stressed,

Bisan pa ug lain sa pandinig sa uban Maam, makaingon jud ko important siya in some ways kay through ani nga language namo, maka-create mi ug friendship ug bonding kay we have the same thoughts and ideas. IDI $7 d$

(Though others might hear it negatively, I can say that it is important in some ways because it creates bonding and friendship as well as having same thoughts and ideas.)

In the same way, another response was added,

Important siya in a way nga makahatag siya ug strong bond in terms of relationship sa among mga friends. Tungod aning Davao-Conyo, mas daghan pa ko ug nahibal-an aside sa language, mas develop pa pud ang friendship, closeness...so, important jud siya Maam. FGD 1

(It is important in a way that it gives strong bond in terms of relationship among friends. Because of Davao-Conyo, I developed friendship and closeness.)

Moreover, it can be gleaned from the response of IDI6 who mentioned that:

Sometimes man gud, uhmm ang mga older generation ma-irita maminaw sa amoa, usahay ingnon mi ug pa-sosyal, aron ingnon nga rich..pero para sa akoa, dili gud kay como nagstorya mi ug Davao-Conyo dato na dayon. Trend man gud siya sa amoa mga youth today which is importante kay nagkasinabot mi sa among gibati. IDI 6

(Sometimes, older generations tend to irk at us, sometimes they say that we pretended to be rich upon using Davao-Conyo. It is trending in the youth among us which is important.)

\section{Challenging to Learn the Conyo Language}

The second theme expressed the challenge felt by the students to learn the Conyo language for them to speak it. Influence of usage of Davao-Conyo encompassed an immense scope and its effect heavily influenced the younger generations. By using this way of expressions, sometimes they felt difficult thus, they felt the need to exert effort which affected their social point of view towards others. In the following responses of the participants, it was manifested that they felt challenged to learn the language.

Magstruggle ko usahay especially kung dili pa kaayo ko kasulti. At first, medyo lisoran ko so mao nang dili kaayo ko ka-gets kay on process pa man ako pagtuon ug conyo. IDI 1

(I struggled sometimes especially if I am not well-versed. At first, I had difficulty and I hardly understand since I'm on process of learning Conyo.)

To be sure, the comment below dealt with her quandary in learning the language, and it was reflected in the words of another participant. She stressed,

Sometimes maglisud ko ug sabot labi na kung imo kastorya paspas kaayo mag-conyo. Dili dayon ko makakuha sa meaning nga iyang gipasabot. IDI 2

(Sometimes I find it difficult to comprehend when your friend is fast in talking Conyo. I cannot 
Mojica, D. R. S., \& De Leon, M. G. M.

easily get the meaning of what he's talking.)

Moreover, it could be also noted that,

Ang paglitok usahay maglisud ko usahay placement sa words kung ako bang i-English or ako nlng i-Tagalog. Makaconfuse pud siya kay dili man gud conyo paminawon kung puro ra pud Tagalog. IDI 3

(I find it difficult in pronouncing sometimes the placement of the words if I'll use English or Tagalog. It made me confused because it will not be Conyo if it is in pure Tagalog.)

\section{Negative Comments Are Unsuitable for a Conyo Speaker}

The third theme posited the influence of speaking Davao-Conyo to the communication skills of the younger generations. Due to the frequency with which the phrase was employed, the younger generation were sensitive to the sentiments of their peers and classmates. Some of the responses shared by the participants spoke and expressed about their feelings towards other people which made them avoid combined negative comments in using Conyo language.

Kuan Maam...na-realize nako nga kung magtalk ka with your friends using Davao-Conyo, walay negative nga feeling towards them kay you understood with each other. IDI 2

(I realized that if you talk to your friends using Davao-Conyo, no negative feelings towards them because you understand with each other.)

Another participant made mention how she gave consideration on how others may feel when she was using the language,

Easy ra siya sa kapwa nimo nga kabalo mag-conyo however mas lisod siya sa uban nga wala naga-practice ug conyo kay naay mga factors nga i-consider. Basin ma-offend or malain ang uuban pero sa kabalo, okay ra kaayo. IDI 4

(It's easy to your fellow who knew Conyo. However, it's difficult for others and they might be intimidated or mad but to those who knew it, it's okay.)

In addition, one participant also highlighted the importance of understanding one another in communicating,

Ang essence sa communication Maam for me is kanang nagkasinabot mong duha. That's it. FGD 6

(The essence of communication for me Ma'am is that you understand each other. That's it.)

\section{Speakers Develop Confidence in Communication}

This theme emphasized that Davao-Conyo served as the language that helped the speakers of the language develop more confidence in communicating or interacting with other people who were also using the language. Thus, communication was effective and comprehensive since both receiver and speaker understood the message they conveyed and with confidence to the language they were using. The following responses below supported the theme highlighted. One of the participants mentioned that,

For me, important ang Conyo para pud maka-express ta sa atong feelings without hesitation kay if pure English maglisod man ta. At least kung ing-ani, murag TagLish ba dili kaayo halata nga naay mali sa grammar (laughing). IDI 4

(For me, Conyo is important for us to express our feelings without hesitations because we will have difficulties if it was in pure English. With this, it's just like TagLish, wrong grammar was 
slightly observed.)

Additionally, another participant strengthened this theme based on her response that,

Na-realize nako Maam nga makatabang siya kay maski mixed ang words sa Davao-Conyo, maka-build siya ug confidence kay kung mu-istorya ka, feeling nako hawod nako mu-english (laughing)...feeling nako proud k okay maka-istorya ko with confidence. IDI 1

(I realized that was really helped although Davao-Conyo is a mixed word, it built confidence and I felt that I'm good in English, I felt proud in it and talked with confidence.)

Another participant also verbalized that,

Davao-Conyo makes one develop sa skill niya sa pagsulti. Kay ang English ug Tagalog words pirmi man malitok so ing-ana, ma-help jud mi nga madevelop among speech. IDI 4

(Davao-Conyo made one develop his/her skill in speaking. Since English and Tagalog was always uttered, it helped to develop your speech.)

\section{Freedom in the Use of Conyo Language is an Experience}

The fifth theme emphasized that the perspectives of the participants on how they viewed the liberty to use the Conyo language as something that was pertinent for them to be able to express themselves. One participant made mention that,

Ma-consider japon nako nga important ang Davao-Conyo kay mas maka-express jud ka sa imo gibati ug mga gusto nimo isulti especially sa social media. IDI 5

(I considered Davao-Conyo important because through this, you can express your feelings especially when posting to social media.)

Another participant also expressed how she had the liberty to make use of the language however she wanted it and stated that,

You have the freedom to make your own version of Tagalog, Bisaya and English Maam then pwede pud isagol nimo basta masabtan. IDI 6

(You have the freedom to make your own version of Tagalog, Bisaya and English Ma'am and you can also mix words as long as it is understandable.)

This was supported by another participant and verbalized that the only rule she knew in speaking the language was that you should be able to mix 2-3 languages,

Sa Davao-Conyo nga language, ang rule is that as long as ma-mixed ang 3 languages, ok na basta matarong lang ug storya. Buki man paminawon pero yes na lang kay magkasinabot man lang gihapon. FGD 4

(In Davao Conyo language, the rule is that as long as you can mix three languages, it is okay as long as you deliver it properly. It may sound weird but just go on with it since it is still understandable.)

\section{Grammatical Rules are not Necessary in Conyo Language/Conversation}

This theme entailed about the function of Davao-Conyo dialect in terms of its structure as spoken dialect. Unlike English language, Davao-Conyo was considered slang, dialect that was developed by the people who commonly mixed Tagalog, English and local dialects depending on the location. Therefore, there was no specific 
rule as to it used for as long as you know how to speak it by mixing other dialects or language. The responses of the participants supported the claim or statement mentioned above. Their responses specifically pointed the Davao-Conyo as free to use by anybody. A response from the participant would tell that,

Importante para sa ako ang Davao-Conyo kay maski dili siya formal o recognized nga language, makatabang gihapon siya especially magamit namo ang English kay sauna kung pure English dili ko maka-express. IDI 3

(Although it's not formal or recognized as language, Davao-Conyo is important especially in using English because before, I cannot express myself in pure English.)

She strengthened this outlook by adding that,

Ang communication kay mi-improve gamay but dili jud almost perfect. Ang realization nako is that helpful siya in speaking but not perfect. IDI 3

(Communication can improve a little but not almost perfect. My realization was that it was helpful in speaking.)

Agreeably, this was supported by another participant by stating that,

Informal man jud ang Davao-Conyo Maam so, informal pud ang mga words nga gamiton Maam. Makaapekto jud siya kay kung unsa ang constant use sa words, sa davao-Conyo makabuot ka ug unsaon imo pag-ingon. IDI 5

(Since Davao Conyo language is informal, the words being used are also informal. It really affected how you use the words constantly and you had to decide how you would want to deliver it.)

\section{Discussions and conclusions}

This study had clearly indicated the purpose that was to analyze the terminologies used in Davao Conyo as utilized by the students of Mabini National High School. It aimed to go deeper into the lexical categorization, morphological process and semantic change based from the word and term used by the students. It was in this context that we took the cue to make use of qualitative research methods in my investigation (Lester, 1991).

Morphosemantic Features of Davao Conyo Terminologies Used by Students. Based on the analysis, different terminologies were given by the students during the interview. These terminologies diverged from the usual languages used by students who were speaking purely Cebuano with fellow students. Thus, the Communication Theory of languages which stated that languages were meaningless in themselves, unless these were used in actual discourses. The results of the study revealed that 25 Davao Conyo terminologies used by students. These terminologies included anuhin, galinga, ginastalk, kachaka, kaiba, magtabok, makadagan, makaschool, nagatoo, nakin, ui, mag go, gud, ay, i-say, gina-mix, nag-eat, pagtalk, ma-gets, ma-loading, maka-give, ma-awkward, ma-confident, mu-dominate and gi-mean. Zhang (2015) said that "the different Davao Conyo terms heard from the students had become one of the modern changes in the school community due to the fact that the use of Davao Conyo in school can be attended by a lot of other students that came from different cultural background and languages. Moreover, Betty (2015) the terminology was disclosed because the students' usage of this language was exposed by engaging not only with other students, but also with various individuals when they went out of their own location, which may impact their style of speaking. The language or the terms were directly related to what the students have learned from various people.

It was also found out that some of the words are used differently. The language used in daily life such as the Davao Conyo language differed from the way it was used in formal writing, and also the way it was used in formal speech. Further, Lundell (2017) the use of Davao Conyo was based in the features found both in written 
and spoken language in other contexts. Further, with various experiences in interacting with other people, and interaction with multiple groups of people, student's language utilization has become an integral aspect of the experience in using the language. As a result, students had become very ground-breaking in uttering a variety of language. Further, students had the tendency to be creative and reappropriating language. They also used non-standard forms of language to coordinate with the daily use of language.

Morphosemantic Features Conyo Words Used by Students. It was revealed in this study that there were (25) words Davao Conyo words used by students in their daily conversation. These terms were analyzed using morphosemantic analysis, lexical category, morphological process, and semantic changes. Employing morphological, the study revealed that the words used affixation, and neologism.

Affixation. One of the morphological processes identified in this study was affixation which defined as a word with no change in form and the meaning was not always the same. Based on the result there were (8) terms listed under affixation. Additionally, affixation was a primary morphological device whereby a bound morpheme was attached to morphological base. But the study revealed that most of the terms were using affixation. It was when the word used zero affixation, this means that the term undergoes no changes in form (Finegan, 2018). Lastly, affixation is a word with no change in form. The term affixation is easily understood by checking the root word of the second word. Affix means to add or attach. In learning and studying English Language, it means that the word formation undergoes no changes. It brought functions that yielded to different forms without changing its original one (Arsip, 2016).

It was revealed in this study that there were two Davao Conyo words that used neologism as the semantic change process. The terms used under neologism can be found on the result section of this study. The result found in table (4) provided transparent and reliable information about the words used. Further, neologism referred to the newly created terms, words. and phrases that commonly applied in everyday life but yet to be formally accepted as a constitute to mainstream of English Language standard. In this study, there were terminologies used by the students under neologism (Yule, 2008). In addition, neologism was created newly word or term. It seemed about the occurrence of the greater rate in cultures with the rampant changed of technologies and the more significant information dispersal. A neology was the use of a new word of the use of an existing word but given a new meaning (Yule, 2008).

Another semantic change that occurred was the metaphorical extensions. Based on the result of the study found on the table there was one term used under extended extension. Metaphorical extensions defined and described the meaning of certain expressions that were used to speak figuratively. This means that metaphorical extensions discussed the literal meanings of the indirectly spoken words (Onumajuru, 2017). Furthermore, the metaphorical extension was also referred to as semantic change. In extended extension, the meaning of words was extended to create a semantic link between a new sense and the original (Yule, 2008). The result of this study also showed that broadening was the semantic process identified in Davao Conyo terms. Based on the result, there were three terms used under broadening. Moreover, broadening was the process of the meaning of word that had become general or more inclusive than the original and it increased the sense over time (Akidah, 2015). In this study, the Davao Conyo terms "anuhin", "galinga", and "kaiba" were used differently from its original meaning. Finally, semantic alterations entailed modifications in a word's usage to the point where its present meaning differed from its initial meaning, although in the case of this study, some terms did not change at all (Akida, 2015).

Impacts of Morphosemantic Features. Morphosemantic features and approach affected the communication process of the students utilizing it in various ways based on their ideas they shared.

Speakers Combine Two Languages to Form a Conyo Conversation. Conyo was generally defined as the way of speaking that mixed with an English, Filipino, and Bisaya in a "posh" manner. Davao Conyo, otherwise known as Davao-Tagalog, Tagalog spoken in Davao native language and bordering areas, with huge afflictions of Cebuano. The meaning to Davao Conyo as Davao Tagalog codeswitched with English. There was diversity of 
reasons why Davaoeños chose to speak this language. Some said regarding speaking the standard Tagalog cannot be pulled off perfectly by most, leading them to resort to combine Cebuano words in the manner they utter. This was also becoming a trend, influence to others who do not really speak in Davao Tagalog to use the same way of saying. Addition to the "social-climbing dimension" may also be one of the reasons people said Davao Conyo. Conyo-speaking students were labelled by most "posh" and "stylish". They had the capacity to talk in standard Tagalog but intentionally use Davao Conyo in order to "fit in." Nonetheless, Davao Conyo continued to flourish and to remain alive in the city and neighboring areas. Amazingly, it grown along with implied policies observed in sentence that came out from the mouth of every Davao Conyo speaker (David, 2015). Furthermore, morphosemantics was well known in linguistics as morphological analysis combined with semantic interpretation and classification of words with their lexical category and morphosemantic word alterations and structures (Khosrow, 2017).

Morphology refers to the study of words. Morphemes were the minimal units of words, had meaning and be further subdivided. Thus, two main types: free and bound. Free morphemes happened alone and bound morphemes existed with another morpheme (Wagner, 2019). Hence it is also given meaning as the semantic analysis of words through their constituent morphemes. Morphosemantics can give a valuable resource for getting access to the underlying definition of words in polysynthetic languages, as lexemes often originate from the aggregation of numerous morphemes, frequently resulting in essentials that go beyond the surface meaning of the lexeme. Morphosemantics has lately been used in automated classification, parsing, and interpreting terminologies and scientific terminology, medical and social terminologies, and jargons (Namer \& Zweigenbaum, 2015). Further, morphological analysis was an attempt to capture the structure of language at the level, thus its concern is on forms of word (Matthew, 2015).

Morphology deals with how words categories were composed. An example of this was how a morpheme was arranged during the developmental stage of the word. A root morpheme was essential as it carries the primary meaning. It was introduced by Zwicky in 1948 who became successfully used in the construction of reaction engines. Altercations in semantics or lexical definition change was a modification in the definition of words - from increase in lexical objects. Typically, semantic change was referred to a comment that acquired a new meaning. For example, e.g. wife from an adult female to a married female.

A new word was born or borrowed, e.g., chiffre from Arabic sifr, the word sandwich was a good example. The common noun "sandwich" was clearly a different word from the proper noun "sandwich" part of the title of its associated person - Eare of "Sandwich" from which was derived. There was a derivation which had a process called eponymy, e.g., when the name of a place or person as a common noun used. On the other hand, vocabulary altered quickly as new words that were borrowed from other languages, or as words get combined or shortened (Lyons, 2015). Thus, variations in definition, common as variations in form; like the latter can be internally or externally motivated. The corresponding to the paradigm morphology was the semantics. It pertained that the word field in which words and definitions stood in a network of relationships. Modification of definition happened because words that were utilized and what was intended by speakers were not exactly the same each time. Different intention for a word was shared by the speech community and became established in usage, then a semantic change had happened (Dasher, 2015).

Traditional methods to semantic change focused on the outcome of definition change and listed several forms of variation such as metaphoric and metonymic expansions. Widening and narrowing, and the improvement of positive and negative definitions. Examples were generally considered out of context, and are lexical members of nominal and adjectival word classes (Yule, 2008). Moreover, morphemes were described as morphological atoms which are the ultimate elements of morphological analysis (Haspelmath, 2017). Thus, words were composed by mixing together by more minor elements to formulate such more significant words to more complex meanings resulted to morphologically complex comment (Plag, 2018).

Recognized how intricate lexical items were completed by the connection of different constituent 
morphemes, then we can analyze any complex word into its various constituents (Haspelmath, 2017). According to Yule (2008), there were various kinds of changes. The most impartial way of referring to modification was simply to speak of semantic shift which was spoken without stating what kind. To start with a sequence of changes which were designed to acquaint learners about was possible in the semantic change. The following processes were becoming inclusive of extensions (metaphorical extension), widening and neologism. The extended extension was considered as the process in which the words and definition can be altered. It pertained to a comment that gained an additional meaning when it was employed in original context, for example, the word "mouse" to mean the computer pointing device in addition to rodent.

Cliff (2018) said that the semantic analysis was considered a method of connecting syntactic forms resulted the level of phrases, clauses, sentences, paragraphs to the level of the writing as a whole and to language-independent definitions. Moreover, it elaborated detaching structures particularly to a specific language and cultural context which gave an extent of project considered possible. Similarly, Moyano (2019) semantic change entailed to the modification of the relationship between a word and a cluster of referents that a specific term may denote. Altercations in the definition conveyed by words brought excellent marks to the lexemes and the morphemes. Hence, there were semantic shifts that were applicable in both lexical and grammatical notions. The connotation of a word was becoming identified in morphemes which were linked and used to a specific language. Some of these were predefined definitions while others vary, depending on the vocal styles used. Furthermore, Isguder (2015) there were morphosemantic properties related and aligned to the morphology (morphemes) and in semantics (meaning). Further, it may also be given importance as the semantic analysis of words through their constituents' morphemes.

Conversants in Conyo were Good to Hear. Most people were agreed that the development of Davao Conyo in industries including the entertainment industry and the social media were good and beneficial because of two common points (Hernandez, 2018). First, it declined the people's perception of an elitist language in Davao to a more straightforward form of an entertainment and proved how dynamic language. There was also a prejudice against conyos thinking that mot, if not all, were "maarte, feeling mayaman and social climbers." Second, it offered the Davaoeños a particular identity mirroring the complexity of language made bare because of the diversity of culture in the area. This point fitted that conyo talk was being a cultural identification of its speakers with linguistic different backgrounds. Furthermore, speakers do not communicate in this manner out of spontaneity, but rather to consciously create boundaries around their territory (Garvida, 2012).

Another Way of Teens' Expression and Conversation. There was central point in language development which was the enrichment or expansion of its terminology, the created words after a certain period of time which was apparent and ambiguous can go in as new stocks in English vocabulary and style. This gave instant, relentless and regular linguistic change and growth. Those words were considered as evidence of the visible changes in the language especially in the English vocabulary (Akunna, 2015). There was affirmation that the essential flexibility of human language with its difficulty and creativity which it was used brought causes to variable and to be modified in time. Oftentimes, totally new verbal signs were added as new word creation in language. The latest styles came from whole had a background in an inventive writing, movies and games. A lot of patchwork creations where originated and traced into the mixture of existing word styles (Dent, 2015). Language components were different within a single location or region, maybe due to international connections and the development of hybridity between individuals of diverse culture and language, resulting in the formation of "third space" or a way of adjustment. This yielded to another form communication that may emerge in aid and satisfaction to communicative requirements. This was maybe the main reason for the rise Davao Conyo as an emerging dialect, and how the use of this emerging dialect was framed in meme cultures which gave impact to the way people's view Davao Conyo local speakers.

Sender and Receiver in Communication Process Easily Understand and Comprehend the Message in Conyo Language. The social networking sites (SNSs) such as Facebook indeed attracted millions of teenagers especially that they were born in a digital world. This hugely widened the English vocabulary. Meaning of 
well-known words had shifted drastically. This opened the gate of newly formed words, new expression or an innovation of an already existing words or phrases. Words were the primary elements of every language; thus, these became the medium of any altercations in the language. Vocabulary was considered as the initial way of interaction and the process of language modification (Akunna, 2015). English in the Philippines had a wide range in its usage and gave an extended register and unique style in range. It had a long history and had penetrated deeply at all levels of society (Bautista, 2004). Morphological change was any altercation, addition and omission of one or more morphemes of a word which was resulted in the morphology of English changed. Modifications included its function, definition of morphemes, inflections in paradigms and patterns. Similarly, English inflections lost because of the representation of the grammatical function on nouns, e.g., doer, receiver, beneficiary. This morphological process changed in stems to derive new words.

Many kinds of process which were presented and can be found in all languages. These were concatenative, involving the linear combination of morphemes (affixation, for example), while others were non-concatenative, including the alternation of internal morpheme features (Finegan, 2018). Thus, morphology was the study on how the words were formed. The following morphological processes were compounding, clipping, initialism, acronym and zero affixation. Compounding refers to two words combined, retaining the totality of both comments. It merged two or more stems to form a new word that was stored as a single entry in the lexicon, e.g., 'blackbird' or 'three-year-old'. The meaning of a compound was not affected by spelling. Others were represented as one word as in 'housefly', hyphenated as in 'extra-terrestrial', 'out-of-pocket' and separated by a space e.g., 'kill-joy' (Finegan, 2018).

Semantics was a substitute linguistics that dealt with the meaning, which included the definition of words, phrases, or sentences. It attempted to comprehend the importance of an element of language, how it was constructed by languages as well as how it was interpreted, obscured, and dealt with by speakers and listeners of language (Merrindah, 2016). Furthermore, it highlighted that it has scope of semantic meaning which was seen from two perspectives namely the narrow and broad sense. When it was the little sense, semantic referred to the study of importance in the lexicon alone especially from the traditional perspective. On one hand, when it was the broad sense, it referred to importance of words and higher units in grammar such as phrases and sentences as well as word meaning changes. Additionally, semantic analysis generally dealt with definition in language (Matthew et al., 2015).

Students' Insights in Using Davao-Conyo in Local Setting. This major theme displayed how the student-participants view their use of Davao Conyo and what's its impact on their day-to-day activities. Their views on their utilization of the language reflected about how important the use of this language for them and what their underlying reasons were for utilizing this kind of language.

Establish Bond and Companionship. For the Philippines, what exists were three circles within this Outer Circle. There was an Inner Circle of educated, elite Filipinos embraced the English language (whether standard American or Philippine English) and actively promoted and protected. There was an Outer Circle of Filipinos who may be aware of Philippine English as a distinct and legitimate diversity, but who were either powerless to support it and, or ambivalent about its promotion. And there was an Expanding Circle of users of English in the Philippines to whom the language, of whatever variety, remained a requisite to upward mobility but was also largely inaccessible (Martin, 2014).

Challenging to Learn the Conyo Language. 'Conyo' (from the Spanish coño meaning cunt) had taken on having new meaning of words and phrases in the Philippines. Coño was also an interjection. According to numerous anecdotes told in the past, when Spaniards came and used to give ending in sentences and words. Former Spanish colonies began, the coño became a synonym of Spaniard as well, as yelled by a Chilean patron when heard by the Peninsular Spanish accent in Delibes' (1995) Diario de un emigrante: “¡Pucha, un coño! ... que había querido decir español!” (Darn, a coño! ...in Spanish language). The typical Spanish exclamation had chosen up as well as by the Filipinos and being refer to Spaniards, used to indicate a person who belonged to 
upper middle class, fair skin (that is, of Caucasian background), and was living in an exclusive neighborhood. Thus, it was very reminiscent of the colonial times. In Philippine context 'conyo' had no natural connection being signified and the object was understood by the representation of the originality (Garvida, 2012).

Negative Comments were Unsuitable for a Conyo Speaker. The stable linguistic influences had resulted from contacts with diverse peoples and cultures. A word or phrase acquired a new meaning among a specific group of individuals that was distinct from its original meaning of "a meeting of cultures in the intercultural realm resulting in irreversible intracultural alterations" (Mey 2007 as cited by Garvida, 2012). The situation was frequently observed among multilinguals who "established functions of linguistic heterogeneity which went beyond the expressive possibilities available in a single code", and most of the time, the translations or interpretations brought signified to its figurative fate. Another point was that Davao Conyo did not represent the Davao community as a whole, since it was just primarily evident to students especially for students who came from various places around the country with different dialects. There were also Davaoeños who believed that the perception towards Davao Conyo differed and relied on its utilization and the composition of the videos or memes made in social media (Hernandez, 2018).

It did not impose good or bad, it was subjective by how people perceived it and how it was presented and it was the only a new breed of identity branding had various cultural backgrounds. This can be connected to the theory of intercultural praxis which basically showed how to deal with communication barriers (Sorrells, 2016). Furthermore, a significant aspect of a language analysis was the exploration of the form of the words and their organization into the grammar of a language. A language satisfied the communicative requirements of the society and people using it when specific policies were observed in the creation of linguistic expressions. Lexical category was a unit of categorization of words in the grammar of a language and which served to portray the unique configuration characteristics of particular terms and word classifications. Additionally, the rise of the new language was ascertained to be a medium to comply for Davao's linguistic diversity (Aigbedo \& David, 2015). It had recently started to make itself known nationwide through social media. Davao Filipino/Davao Conyo in Meme-Culture" context online was perceived as a source off laugh and entertainment. But, beyond that, it was unknown what Davao Conyo was as a burgeoning colloquial language and how it rose and was employed in the entertainment business, which had an influence on the language's local speakers. (Dolalas, 2017).

Speakers Develop Confidence in Communication. There was a solution to intercommunication challenges in the preceding decade where Filipinos leaned on dialects customized to their own altering communicative demands. 'Conyo' talk had an emulation of how English and, or Spanish speakers communicated to native Filipinos. It had become a bearing among the middle class, the chosen means of communicating with others and had established potential relations (Garvida, 2012). The paper entitled "The Nature of Conyo in Davao City: A Language Inquiry," pertained about the mix language as Davao Conyo due to the stature and increased confidence that speakers felt in speaking. In Davao City, speaking Filipino become the basis on status in society and the way of living (Albino et al., 2016).

Compounds can be endocentric or exocentric. It was transparent from the definition of its constituents. On the other hand, it was a kind of its head (as blackbird is a type of bird). An exocentric compound was not as quickly known and comprehended because of the total components. For example, a 'pickpocket' was not a kind of pocket but who picked objects from bags. Moreover, Clipping referred to a word formation processes that were comprised in the subtraction one word to its parts. These were not created as words fitted in to the typical vocabulary of a language. It started as standings of a particular cluster like exam(ination), lab(oratory) and vet(eran). Initialism was a sequence of initials utilized as a word. It was a group of marks having representation of a name, organization and other entities, with every letter pronounced individually e.g., as FBI for Federal Bureau of Investigation. On another hand, Zero Affixation was a word who undergone no variations in form, in addition, the definition was not always the same.

Morphology was referred to word formation. Words were usually recognized as being the tiniest unit of 
syntax. In other languages, words can be linked to other words by rules. The guidelines understood by the speaker particularly the patterns and its ways. The words were organized from lesser units and how smaller units interrelated in speech. Thus, morphology was the part of linguistics which had patterns of word formation across and within languages and attempted to explain the proper directions reflected speakers' knowledge of the language. Morpheme was the most minor expressive language and grammatical function (Finegan, 2018). Furthermore, it gave emphasis that the morpheme could stand on it singly and required by varied with at least one other morpheme to form a word. Morpheme which can stand singularly also called as free morpheme or root. The morpheme which entails to be attached with another morpheme was known as a bound morpheme or affixes. Examples were dogged, daily, foolish. One of the biggest bases of complexity in morphology were one correspondence between definition and form which did not apply to every situation in language context. In English language, there were words that form pairs like ox/oxen, goose/geese and sheep/sheep where the difference had considered between singular and the plural signaled in a way that shifted from the usual pattern or not being signaled (Wilkims, 2015).

Freedom in the Use of Conyo Language is an Experience. There was a study entitled "Davao Filipino and its Literary Possibilities," theorized the mixture of language as a Filipino range. The basis scrutiny on Platt's three-dimensional continuum of Singlish. A creole continuum of Davao Filipino language was considered that the 'standard Filipino' at the acrolectal level. The regional language was impacted at the mesolectal level, whereas Davao Filipino was influenced at the basilectal level. It was decided that creolization, as defined by Rickford (as quoted by David), and the sociolectal gradation of language gave touch to the significance and efforts involved in building an original cultural identity or new ways of creative expression. Finally, when discussing creolization, the formation of a sociolectal of Davao Filipino must be examined through a postcolonial lens, with the acrolect serving as the colonial language (Demetrio III \& Dreisbach, 2017).

Grammatical Rules are not Necessary in Conyo Language/Conversation. In modern English, vocabulary change sometimes became a problem socially. This was because some people reacted negatively to these modifications feeling that the language, they were used to become downhill, disadvantageous and hinder communication. In today's generation, those who were frequently using social media were those who were more conversant (Akunna, 2015). On the one hand, some local speakers of Davao Conyo also believed that the increased fame of Davao Conyo had negative views and implications both to them and the language itself as well. A point that emerged on the study that the emergence of Davao Conyo eventually led to Davaoeños' losing their authentic dialect which was Cebuano or Bisaya. It was mentioned that the fusion between these languages held a risk against the survival of pure Cebuano as it allowed Tagalog to interpenetrate, that led to the decrease in people's interest for the dialect based on (Dolalas, 2017).

\subsection{Implications for Teaching Practice}

Comprehending the language utilized by most students were challenging without the appropriate guidance more so on the morpho-semantics features of the words and terms. This study provided and imparted further knowledge in exploring the morpho-semantic features of the language and how it affected the communication process especially in the field of English specifically on the expansion of vocabulary and teaching English where the communication skills of the students were being enhanced. In the context of the teaching practice, the use of Davao Conyo, based on the outcomes of the study taught and informed the students to disregard the rules of grammar especially that Conyo language that does not necessarily have the grammar rules to follow in integrating the English language. As an English teacher, the researcher deemed it unnecessary to motivate students in continuously using the language.

Particularly for the English teachers, one of their functions was to gain knowledge and understanding of the vocabulary used by the students. The results helped the teachers in understanding the system of the language. In addition, the result was an endeavor or a platform for teachers to help those students to improve or to enhance their communicative skills especially for those students who did not participate in the classroom by allowing 
them to use the words they were comfortable with in expressing whatever sentiments and ideas. There was a need to understand the use of Davao Conyo language by the students first. Moreover, with the impact brought about by the morphosemantic features of the language, they established interventions in helping the students overcome the challenges of switching from "text speech" to formal writing that includes proper spelling. This is not limited to local languages, but is also quite common with other languages besides English and Tagalog, for instance can also be found in Chinese and other dialects (Lin et al., 2021). With this, it aided them regain their communicative skills.

Additionally, with the result of this study, the teacher formulated new ways of teaching to the students about the grammatical usage of the terms. It was unavoidable that students can incorporate phrases or words they were using inside the classroom in speaking and writing activities as these were their ways in expressing. The results considered as helpful in guiding the teacher by providing appropriate feedback in the usage of the language especially its correct usage in writing and speaking. Therefore, the results implied for enhancement in the teaching patterns of speech that teachers taught and imparted the students the social use, how and when to use the words to express its appropriately and accordingly the functions. This was due to the fact that some students used a specific term but did not exactly knew how and when to use it properly. Further, this contributed to the advancement of English for Specific Purposes (ESP) that the words or terms gathered belong to the students' register. This served as expansion of vocabulary. With the outcome yielded, it helped in the field of ESP in meeting the particular needs of the learners. Additionally, this study assisted in better understanding on various students to avoid miscommunication. Also, knowing the results of the study, there was a need to provide interventions to uphold communication skills of students so there was no room for the possibility of losing their skills in technical and academic writing.

\subsection{Recommendations for Future Research}

The discourse analysis was limited only to the morpho-semantic features of the language hence, it only explored on the morphological change and semantic change processes. The results played a vital endeavor as reference for future researchers who would like to delve into similar subject. However, to make this research more substantial, it was recommended to gather increased number of research materials in order to get away from the few words or terms picked. It was also recommended to broaden the setting or locale of the study since this study focused only locally for there were also various Davao Conyo terms used by other students which were not also utilized by other students. Also, since this study employed qualitative-discourse analysis, a further exploration can be considered by future researchers. The used of quantitative or mixed method research design may be undergone to further explain how often were these terms used and its effect to students' academic achievement.

Additionally, for further exploration, qualitative research using phenomenological inquiry can be considered to explore further the experiences of students in utilizing Davao Conyo in their daily conversations. Similarly, because this study was conducted and participated in by students who used the Davao Conyo language, it was also suggested that this study be conducted in which teachers who encountered and faced students using the language will be interviewed about their experience in dealing with these students as well as their views and perspectives. Also, it was recommended that the study conducted focused on patronizing and exploring the effects of Davao Conyo to the students, teachers and other people that they interacted and communicated.

\subsection{Concluding Remarks}

Doing this study was a great challenging, but I hurdled it with full of zealous effort. It was really fascinating even if there were so many arduous treks as I journeyed this. Patience, hard work and perseverance were required to finalize the mission of making this study momentous and to reap the rewards of success. As I conceptualized my research title, I thought about it for many times, the struggle of conceptualizing was encountered in order to make a decision on what really caught my interest. Then, patiently I had come to choose 
carefully and accordingly of conducting this study. With the aid of my adviser and analyst, it helped me to unmask the Davao Conyo terms and words used by students. It helped me to be aware of what actions were required to me in order to teach the students better.

There were various people who can identify us, but only few people understood us. Utilizing Davao Conyo was one way to develop social and intellectual skills. It gave an avenue and guiding stars for others to be able to express themselves. Following the observation and gathering of facts via interview and focused-group discussion, I obtained adequate information that served as my tool to unlock knowledge in the various processes observed in the use of Davao Conyo language, which included, but was not limited to, morphosemantic features, morphological methods, and semantic change processes.

In this study, it was apparent that language was ever-changing. A number of students opted to utilize a language based from how they heard it from other people not natives of their locality such as the use of Davao Conyo. This study allowed me to explore the incredible possibilities on linguistic aspects of the language that provided and aided me with new experiences such as the challenge of unlocking the Davao Conyo terms used by the students, analyzing how the morphosemantic features of the language affected the students' communication process, and listening to the students' insights in their utilization of the Davao Conyo language. Further, analyzing the words utilized by the students were tantamount to understanding what they were saying. Also, I had seen that the students needed help in terms of how their communication skills become at risk to be affected especially in disregarding the rules for using grammar. They need really some attention and guidance. Further, the terms used by students in speaking Davao Conyo evolved in the fields of socio-linguistics such as morphemes and context. It had been widely utilized by incorporating it in the casual conversation among another student. This evolution of terminologies derived the linguist and language researchers into a tremendous linguistic challenge.

In addition, outcomes of the study suggested that Davao Conyo had its own manner and style of utterances. This study had made it known about utilizing and speaking on Davao conyo language. This research aimed to aid, direct, and provide information to the following students' generations who might be interested to further educate topics related to Davao Conyo. Moreover, student-participants and students in general benefited from this study about the facts on concentrated language. The primary purpose of the study was about Davao conyo which aimed to confer and to share information on tongue. Another benefit that students got from this study were the knowledge on morphosemantic features of the Davao Conyo language particularly the morphological process and semantic change processes of the language. Also, students as well as student-participants can gain knowledge on how the use of Davao Conyo language affected to the linkages towards the communication process based on the outcomes yielded on this conducted study.

Because the purpose of this study was to impart knowledge and learnings about the use of a language other than the one commonly used in Davao de Oro, it was also beneficial to teachers, particularly those who were significant in English, in the sense that a study provided and gave ideas and discussions that would be useful in the aspect of language. The researcher knew that this study can be beneficial and informative in solving some questions, confusions and problems related to the students' who were using the Davao conyo language. It aided the researcher understand the other people's way of communication through accepting diversity in differences and its uniqueness despite the varied backgrounds to be considered.

Further, this research guided the researcher to be open minded on how to avoid discrimination to the speakers of Davao Conyo language. In addition, the conduct of the study had made the researcher realized how dynamic language and how a simple language spoken by students had various features and processes linked to it. Finally, the researcher learned to appreciate the uniqueness of the use of varying language such as the Davao Conyo language. Therefore, English teachers should know that it was not adequate only to comprehend what they said and to know what words they use mean, this also called for an attention that their practice was leading them to a great challenge of reviving their trending communicative skills. With this in my mind, it helped me as 
a researcher to be inspired to learn, to understand and to unlock more the new terms and languages utilized by the students.

\section{References}

Adams, T. E. (2008). A review of narrative ethics. Qualitative Inquiry, 14(2), 175-194. https://doi.org/10.1177/1077800407304417

Agbedo, C. U. (2000). General Linguistics: An Introduction Reader, Enugu: Magnet Business Enterprise.

Aigbedo, C. (2015). Deconstructing myths via humor: A semiotic analysis of Philippine political internet memes. Retrieved from https://www.msuiit.edu.ph/academics/colleges/cass/research/langkit/2016/1-20.pdf

Akidah, N. (2015). The Nature of Conyo in Davao City: A Language Inquiry. Retrieved from https://www.arcjournals.org/pdfs/ijsell/v4-i1/9.pdf

Akunna, O. (2015). Social media neologisms: A morpho-semantic analysis. Retrieved from http://www.academia.edu/8169243/

Amorado, R., \& Talili, I. (2017). Qualitative Research: A practical approach for senior high school. Manila: Mutya Publishing House, Inc.

Arsip, P. (2016). Meme world syndrome: A critical discourse analysis of the first world problems and third world success internet memes. Retrieved from http://etd.fcla.edu/CF/CFE0004828/Chandler_Robert_C_3127154_MA.pdf

Bautista, M. L. S. (2004). Tagalog-English code switching as a mode of Discourse [Electronic version]. Asia Pacific Education review, 5(2), 226-233.

Beatty, K. (2015). Computer Assisted Language Learning. London: Longman. Retrieved from https://actf1.org/sitedefault/Caef/AppendixM-ACFTLStatementRoleofTechnology.pdf

Bista, K. (2015). Factors of code switching among bilingual English students in the university classroom: a survey. Retrieved July 10, 2020 from http://www.espworld.com/Articles_29/Factors.pdf

Bullock, B. E., \& Toribio, A.J. (2009). Conceptual and methodological considerations in code-switching research.

Cliff, H. (2018). Davao Filipino and its literary possibilities. Retrieved from https://academia.edu.documents/37258675/.pdf

Creswell, J. W. (2007). Qualitative inquiry and research design: Choosing among five traditions. Thousand Oaks, CA: sage.

Creswell, J. W. (2014). Qualitative inquiry and research design: Choosing among five traditions. Thousand Oaks, CA: sage.

Dasher, R., (2015). Internet memes as an example of political dissatisfaction of poles on the internet. Retrieve from http://cejsh.icm.edu.pl/cejsh/ element/bwmeta1.element.desklight-b81daa61-b6c3-49be- 8ab8-e72 $8 \mathrm{c} 87893 \mathrm{ea} / \mathrm{c} /$

$\underline{\text { Kobierecki-M.-Internet-Memes-as-an-Example-of-Political-Dissatisfaction-of-Poles-on-The-Internet.pd }}$ f

David, D. (2015). Follow Them, Closely. Social Media + Society. https://doi.org/10.1177/2056305115578134

Delibes, S. (1995). Language and Ethnicity. John Benjamins Publishing.

Demetrio III, J., \& Dreisbach, M. (2017). The Cambridge Handbook of Linguistic Code-switching.

Dent, S. (2015) The Language Report: The ultimate record of what we're saying and how we're saying it. Oxford: Oxford University Press.

Dolalas, L. L. J. (2017). Davao Tagalog: Endangerment of Binisaya language. Retrieved from http://www.academia.edu/2499342/Davao_Tagalog_Endangerment_Of_Binisay a_Language

Dorgeloh, J. (2009). The Importance of Being Bilingual. Bilingualism: Beyond Basic Principles. Multilingual Matters.

Dougherty, D. S., Mobley, S. K., \& Smith, S. E. (2010). Language convergence and meaning divergence: A theory of intercultural communication. Journal of International and Intercultural Communication, 3(2), 164-186. https://doi.org/10.1080/17513051 003611628 
Mojica, D. R. S., \& De Leon, M. G. M.

Evmorfopoulou, K. (2007) Focus Group Methodology for the Madame Project.

Finegan, M. (2018). Associations between socioeconomic status and Psychological outcomes: A systematic review and meta-analysis. https://doi.org/10.1002/da.22765

Frey, B. (2018). The SAGE encyclopedia of educational research, measurement, and evaluation (Vols. 1-4). Thousand Oaks, CA: SAGE. https://doi.org/10.4135/9781506326139

Garvida, M. M. (2012). "Conyo talk": The affirmation of hybrid identity and power in contemporary Philippine discourse. Lingue e Linguaggi, 8, 23- 34. https://doi.org/10. 1285/i22390359v8p23

Giles, H., Coupland, N., \& Coupland J. (2010). Contexts of accommodation: Developments in applied sociolinguistics, 1-68. https://doi.org/10.1017/CBO978051166367 3.001

Haspelmath, M. (2017) Understanding Morphology. New York: Arnold.

Hernandez, R. (2018). Token Level Identification of Linguistics Code Switching. Proceedings of COLING: Posters, pp: 287-296.

Isguder, G. (2015). Using morphosemantic information in construction of a pilot lexical semantic resource for Turkish. https://doi.org/10.3115/v1/W14-5807

Khosrow, L. (2017). Emigranto: The syntax of German - English code- switching. Wien: Braumüller.

Klapuri, K. (2017). Code-switching. Cambridge, UK; New York: Cambridge University Press.

Lin, S.-L., Wen, T.-H., Ching, G. S., \& Huang, Y.-C. (2021). Experiences and challenges of an English as a medium of instruction course in Taiwan during COVID-19. International Journal of Environmental Research and Public Health, 18(24), 12920. https://doi.org/10.3390/ijerph182412920

Lincoln, Y. S., \& Guba, E. G. (1985). Naturalistic inquiry. Beverly Hills, CA: Sage Publications.

Lundell, H. (2017). Revisiting Taglish na naman: A congruence approach to Tagalog-English code switching. Philippine Journal of Linguistics, 31(1), 25-38.

Lyons, P. (2015). Discourse strategies. Cambridge: Cambridge University Press.

Martin, B. (2014). Some syntactic constraints in Tagalog-English language mixing. Unpublished master's thesis, University of Hawaii.

Matthew, S. (2015). Filipino and American online communication and linguistic variation. World Englishes, 31(2), 143-161. Retrieved from http://search.proquest.com/docview/1550992078?accountid=11091

Merrindah, R. (2016). Electronic English in Malaysia: Features and language in use. English Today, 25(4), 39-46. https://doi.org/10.1017/S0266078409990435

Mey, J. (2007). Developing pragmatics interculturally. In I. Kecskes \& Horn, L., (Eds.), Exploration in pragmatics (pp. 165-189). Berlin: Mouton de Gruyter.

Moyano, T. (2019). Geography and spatial analysis in historical linguistics. Language and Linguistics Compass, 8(8), 344-357. https://doi.org/10.1111/lnc3.12087

Namer, M., \& Zweigenbaum, W. (2015). Making MIRACLEs: Interactive translingual search for Cebuano and Hindi. ACM Transactions on Asian Language Information Processing (TALIP), 2(3), 219-244. https://doi.org/10.1145/979872.979876

Norlin, L. (2015). Voices of Authority: Education and Linguistic Difference. Westport, CT: Ablex.

Onumajuru, N. (2017). Codeswitching: Anthropological and sociolinguistic perspectives. Journal of Linguistic Anthropology, 2(2), 214-216. https://doi.org/10.1525/jlin.1992.2.2.214

Palinkas, L. A. (2015). Purposeful sampling for qualitative data collection and analysis in mixed method implementation research. http://www.ncbi.nlm.nih.gov/pubmed/24193818

Patton, M. Q. (2015). Qualitative research: A guide to design and interpretation. https://psycnet.apa.org/psycinfo/199097369-000

Rubrico, J. U. (2014). Filipino Davao variety: A linguistic description. http://www.languagelinks.org/online papers/Filipino-11thPLC.pdf

Shenton, A. K. (2004). Strategies for answering trustworthiness in qualitative research projects. http://www.crec.com.uk/docs/Trustworth paper.pdf

Sorrells, G. (2016). Switching in twitter's hashtagged exchanges. Journal of Business and Technical Communication, 28(1), 83-108. https://doi.org/10.1177/1050651913502358

Tannen, D. (2012). Discourse Analysis - What Speakers Do in Conversation. Retrieved from 
http://linguistcisosciety.org/resouce/discourse-analysis-what speakers-doconversation

Wagner, J. (2019). What is morphology? Retrieved from https://ielanguages.com/morphology.html

Wilkims, F. (2015). Processing of sentences with intrasentential code- switching. In D. R. Dowty, L. Karttunen, and A. M. Zwicky (Eds), Natural Language Parsing.

Willens, D. (1997). Hungarian verbal puzzles and the intensity of language contact. Journal of Sociolinguistics, 5(2), 163-179. Malden, MA: Blackwell.

Yule, G. (2008). The study of language. New York: Cambridge University Press.

Zhang, K. (2015) Written codeswitching in the classroom: Can research resolve the tensions? International Journal of Bilingual Education and Bilingualism, 12(2), 213- 230.

https://doi.org/10.1080/13670050802153228 
Mojica, D. R. S., \& De Leon, M. G. M.

272 Consortia Academia Publishing (A partner of Network of Professional Researchers and Educators) 